\title{
Dynamics and Control of High-Rise Buildings under Multidirectional Wind Loads
}

\author{
Aly Mousaad Aly, ${ }^{1}$ Alberto Zasso, ${ }^{2}$ and Ferruccio Resta ${ }^{2}$ \\ ${ }^{1}$ Department of Mechanical Engineering, Faculty of Engineering, Alexandria University, Alexandria 21544, Egypt \\ ${ }^{2}$ Department of Mechanical Engineering, Politecnico di Milano, Via G. La Masa 1, 20156 Milano, Italy
}

Correspondence should be addressed to Aly Mousaad Aly, aly.mousaad@polimi.it

Received 30 October 2010; Revised 27 April 2011; Accepted 28 April 2011

Academic Editor: Gangbing Song

Copyright ( $\odot 2011$ Aly Mousaad Aly et al. This is an open access article distributed under the Creative Commons Attribution License, which permits unrestricted use, distribution, and reproduction in any medium, provided the original work is properly cited.

This paper presents a procedure for the response prediction and reduction in high-rise buildings under multidirectional wind loads. The procedure is applied to a very slender tall building that is instructive. The structure is exposed to both cross-wind and along-wind loads obtained from pressure measurements on a rigid model (scaled $1: 100$ ) that was tested in a wind tunnel with two different configurations of the surroundings. In the theoretical formulation, dynamic equations of the structure are introduced by finite element and 3D lumped mass modeling. The lateral responses of the building in the two directions are controlled at the same time using tuned mass dampers (TMDs) and active tuned mass dampers (ATMDs) commanded by LQR and fuzzy logic controllers, while the effects of the uncontrolled torsional response of the structure are simultaneously considered. Besides their simplicity, fuzzy logic controllers showed similar trend as LQR controllers under multidirectional wind loads. Nevertheless, the procedure presented in this study can help decision makers, involved in the design process, to choose among innovative solutions like structural control, different damping techniques, modifying geometry, or even changing materials.

\section{Introduction}

Civil engineering structures are an integral part of our modern society. Traditionally, these structures are designed to resist static loads. However, they may be subjected to dynamic loads like earthquakes, winds, waves, and traffic. Such loads can cause severe and/or sustained vibratory motion, which can be detrimental to the structure and human occupants. Because of this, safer and more efficient designs are sought out to balance safety issues with the reality of limited resources. Wind-induced vibrations in buildings are of increasing importance, as the use of high-strength, lightweight materials, longer floor spans, and more flexible framing systems results in structures that are more prone to vibrations. In tall buildings, wind-induced vibrations may cause annoyance to the occupants (especially in the upper floors), impaired function of instruments, or structural damage.

Traditionally, wind-induced response of tall buildings in the along-wind direction are evaluated using some codes and formulas [1-4]. However, these standards provide little guidance for the critical cross-wind and torsional responses. This is due to the fact that the cross-wind and torsional responses result mainly from the aerodynamic pressure fluctuations in the separated shear layers and the wake flow fields, which made it difficult to have an acceptable direct analytical relation to the oncoming velocity fluctuations $[5,6]$. In addition, these methods may have some limitations, especially for accounting of surrounding tall buildings. Moreover, responses are restricted to some few modes, and the process of evaluating such response depends on much assumption. On the other hand, wind tunnel pressure measurements and finite element modeling (FEM) of the structures are an effective alternative for determining these responses. Wind tunnel tests have been industry wide accepted reliable tools for estimating wind loads on tall buildings. For tall buildings, there are two types of testing: (1) high-frequency base balance (HFBB) and (2) high-frequency pressure integration (HFPI). Inherent in the HFFB approach is the fact that only the global wind loads at the base of the test model are known. The test results from the HFBB measurements can be analyzed using frequency-domain or time-domain 


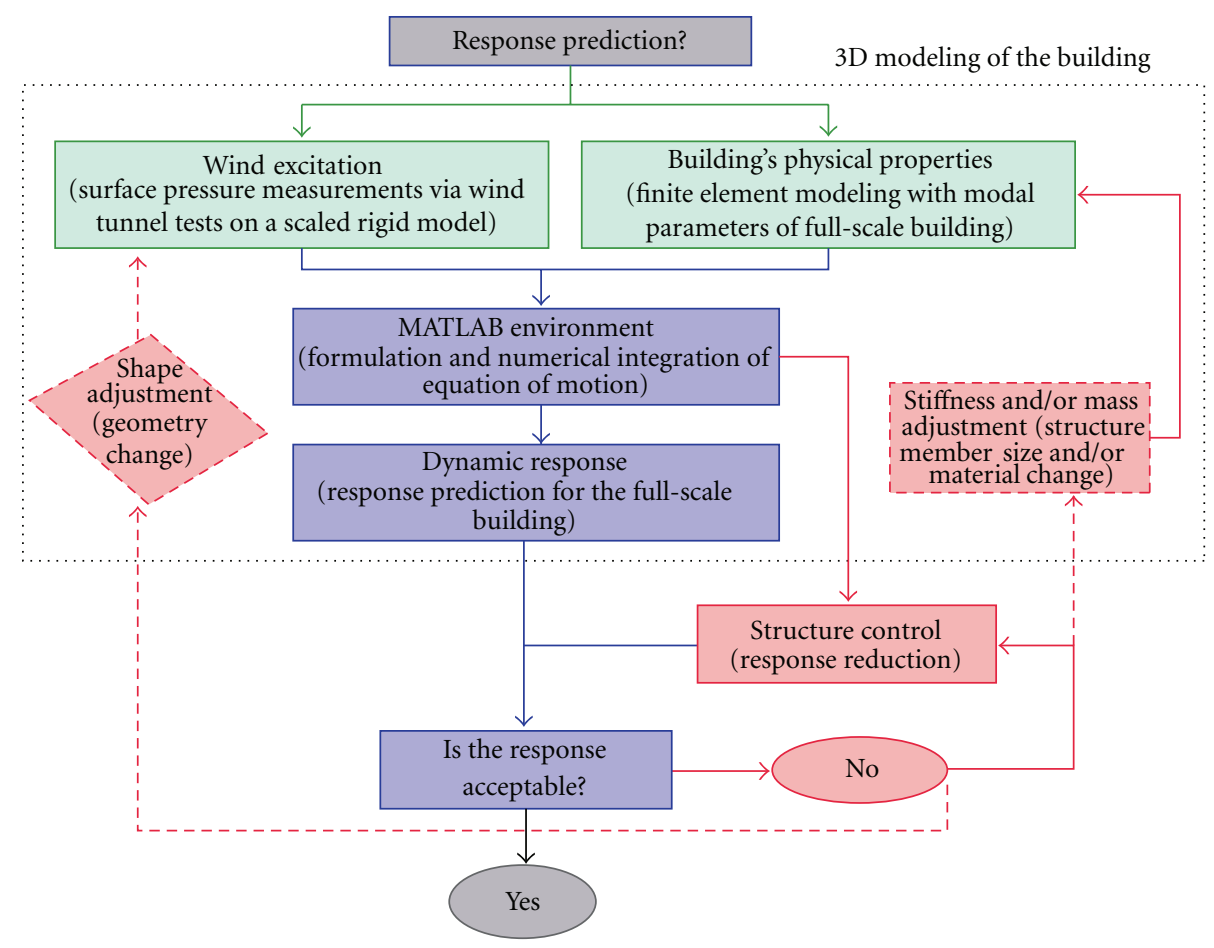

FIGURE 1: Schematic representation of the proposed procedure for response prediction and reduction in tall buildings under wind loads.

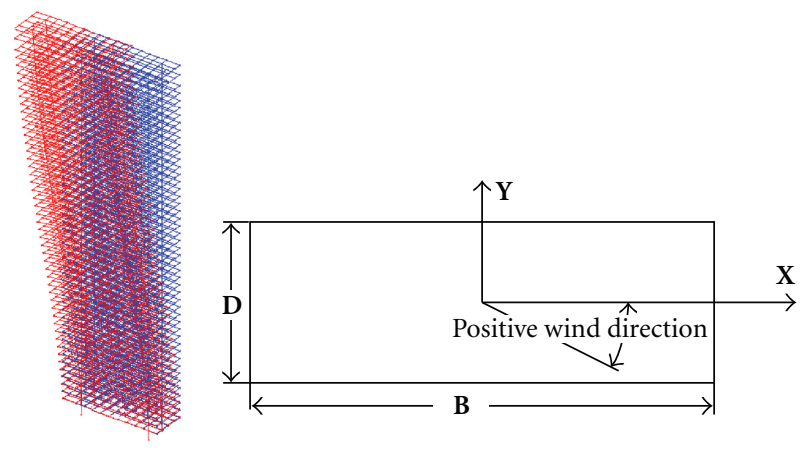

Figure 2: Finite element model with the coordinate system and wind direction $(B=57.6 \mathrm{~m}$ and $D=19 \mathrm{~m})$.

techniques to get the building responses. The frequency domain approach has been dominant over time domain approach for its lesser requirement of computational power though it involves more approximations compared to the time-domain approach. Nevertheless, with the current technology where computational power is no longer a problem, the time-domain method is becoming a popular analysis technique. The time-domain method allows determination of wind responses directly from the equation of motion using the measured time history, thereby avoiding all the simplifying assumptions used in the frequency domain technique [7]. However, even if the more accurate time-domain approach is used for the analysis of the response, the three-dimensional (3D) mode shapes found in complex tall buildings complicate the use of the HFBB test results for predicting the response $[8,9]$. In general, mode shape correction factors for the $\mathrm{HFBB}$ technique are necessary for the assessment of wind-induced responses of a tall building. This is to account for the significant uncertainties in the prediction of generalized forces due to the nonideal mode shapes as well as presumed wind loading distributions [10, 11]. HFPI with the time-domain approach can be more accurate provided that enough coverage of pressure taps on the model's outer surface is performed.

HFPI technique is based on simultaneous pressure measurements at several locations on a building's outer surface. Pressure data can be used for the design of the claddings as well as the estimation of the overall design loads. The HFPI technique cancels out any inertial effects that may be included in the overall loads measured by the base balance if the HFBB technique was used. Time histories of wind forces at several levels of tall building models can be obtained in the wind tunnel with a multichannel pressure scanning system. This enables the building responses to be computed directly in the time domain for buildings with simple or complex mode shapes. Finite element models (FEMs) can be used for describing the dynamic behavior of the structures. HFPI with FEM have the advantages of considering complex shapes of structures with nonuniform mass distribution and can easily account for any required number of mode shapes to be considered in the response analysis.

Preliminary analysis of tall buildings in their preliminary design stages help the designer to make decision by modifying the design or adding passive, active, or semiactive control techniques. Structural control has recently been the subject of much discussion among structural designers. Structural control can potentially provide safer and more efficient structures. The concept of employing structural control to minimize structural vibrations was proposed in the 1970 s 


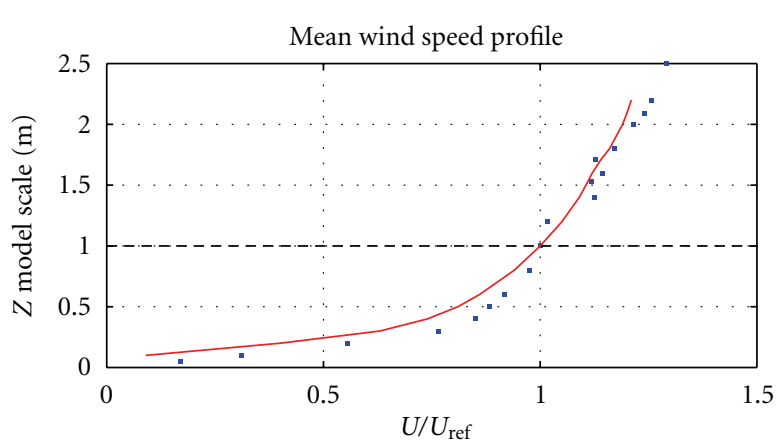

(a)

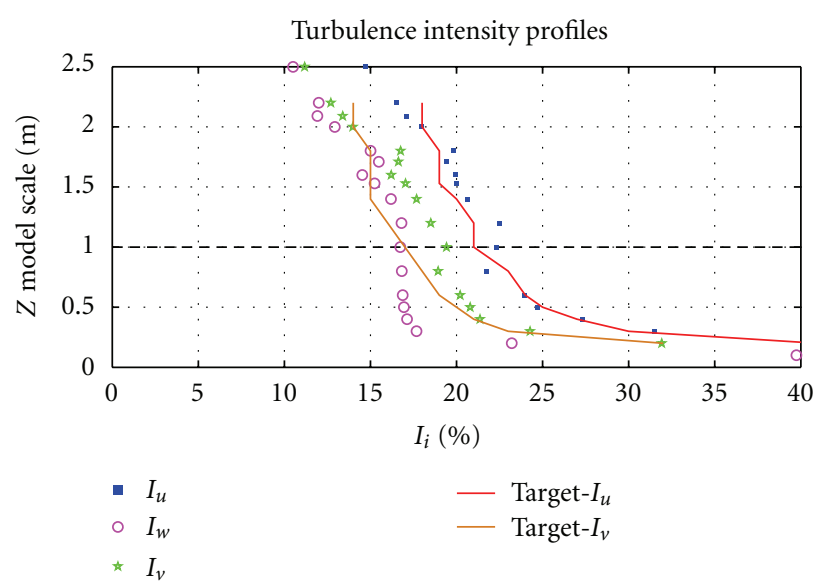

(b)

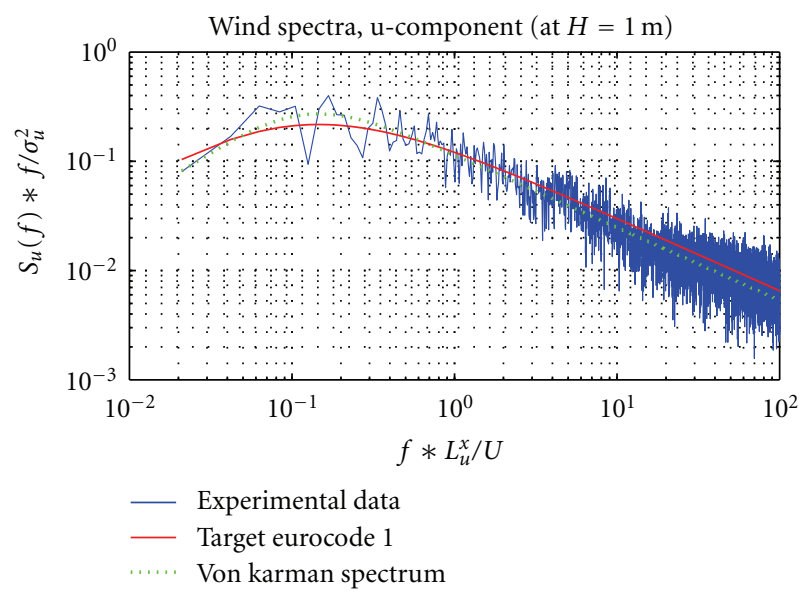

(c)

FIgURE 3: Mean wind speed profile, turbulence intensity profiles, and wind spectra ( $L$ is the integral scale).

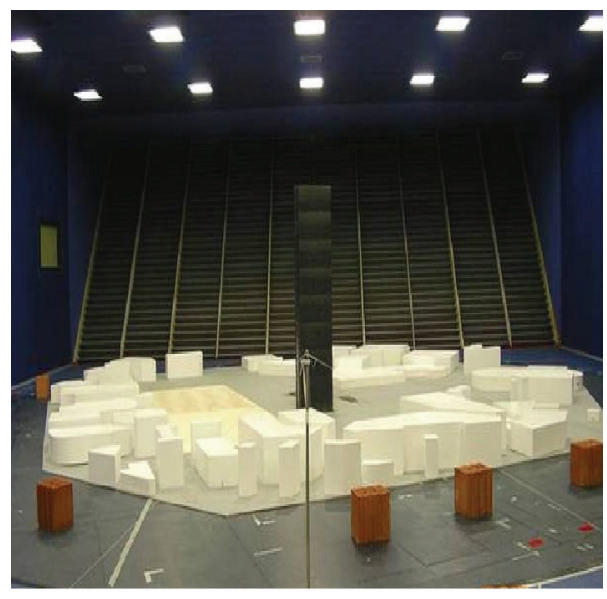

Config. no. 1 (exposure $-67.5 \mathrm{deg}$ )

(a)

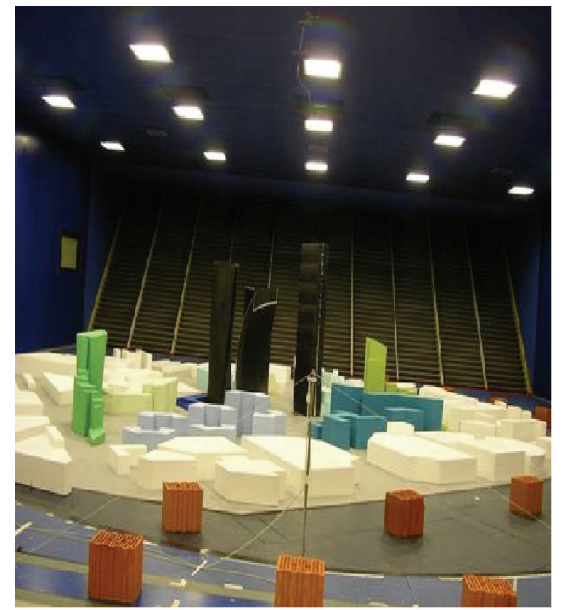

Config. no. 2 (exposure $22.5 \mathrm{deg}$ )

(b)

FIgURE 4: Two different configurations are used. 


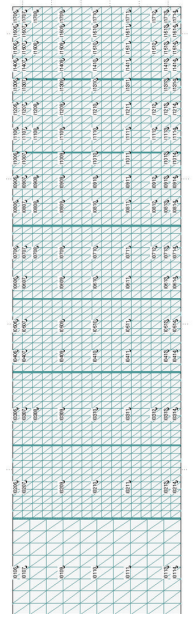

(a)
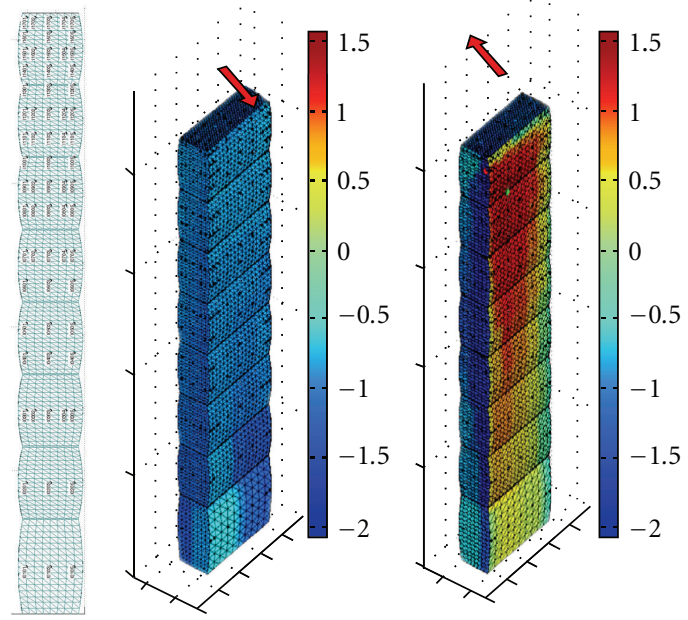

(b)

Figure 5: Pressures on the outer surface of a scaled 1:100 model were obtained from a wind tunnel test: (a) pressure tap distribution (elevation and side view), (b) mean surface pressure coefficient distribution (for $292.5 \mathrm{deg}$ ).

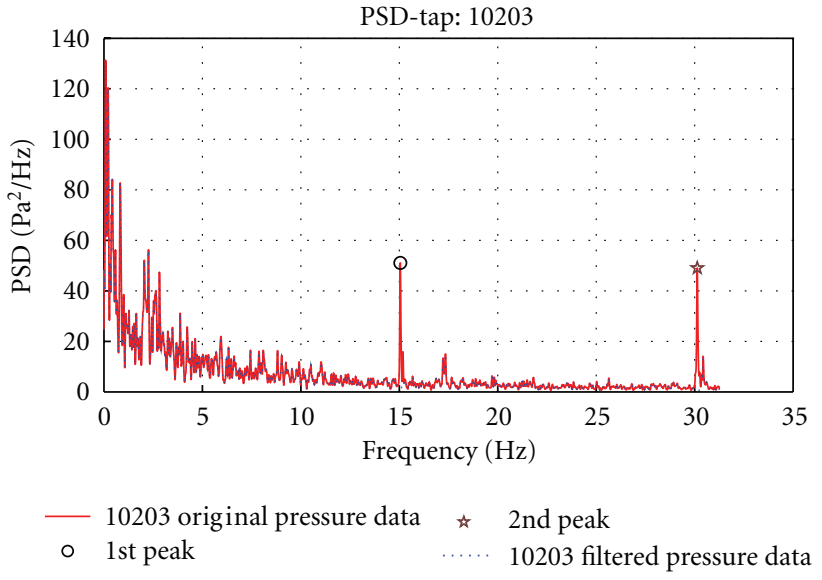

FIGURE 6: Typical spectrum of measured pressure data (at model scale).

[12]. The purpose of structural control is to absorb and to reflect the energy introduced by dynamic loads. The reduction of structural vibrations occurs by adding a mechanical system that is installed in a structure. The control of structural vibrations can also be done by various means, such as modifying rigidities, masses, damping, or shape, and by providing passive or active counter forces [13, 14]. Passive, active and semiactive $[15,16]$ types of control strategies have been proposed.

McNamara [17] studied the tuned mass damper (TMD) as an energy-absorbing system to reduce wind-induced structural response of buildings in the elastic range of behavior. Active control techniques are studied intensively for the control of the response of tall buildings under wind loads [1822]. The most commonly used active control device for tall buildings is the active tuned mass damper (ATMD). TMDs and ATMDs are shown to be effectiveness in the response reduction of tall buildings under wind loads [23-28].
The aim of this study is to present practical procedure for the response prediction and reduction in a very slender highrise building under multidirectional wind loads. The procedure is schematically presented in Figure 1. Wind loads were obtained from an HFPI experiment conducted in a wind tunnel. The tower responses in the two lateral directions combined with the torsional responses (effect of higher modes on the responses is studied) are evaluated. Two important voids associated with procedures to aid in the design are considered: the first is on the distributions of the wind loads; the second is on the effects of the higher modes. Consideration of these two problems needs wind tunnel pressure measurements on the surface of the building and FEM. The building is modeled using the finite element techniques and a 3D lumped mass model. The uncontrolled responses obtained using the two techniques of modeling are compared. Active control of the structure using LQR and fuzzy logic controllers under wind that is attacking from different directions is proposed. In this study, the lateral responses of the building in the two directions are controlled at the same time, while the effects of the uncontrolled torsional responses of the structure are simultaneously considered.

\section{3D Modeling of the Building}

A 48-strory steel tower proposed in Aly et al. [23] is used in this research. The FEM of the tower, along with the coordinate system, is shown in Figure 2. The full-scale building has a height of about $209 \mathrm{~m}$ and a rectangular cross section of $B / D \approx 3$ ( $B$ : chord length and $D$ : thickness). The aspect ratio in the $y$-direction is about 11 , which makes it very sensitive to strong winds. Modal parameters of the FEM for the first six modes are given in Table 1.

2.1. Equations of Motion in Modal Form. Equations of motion governing the behavior of the structure under wind 


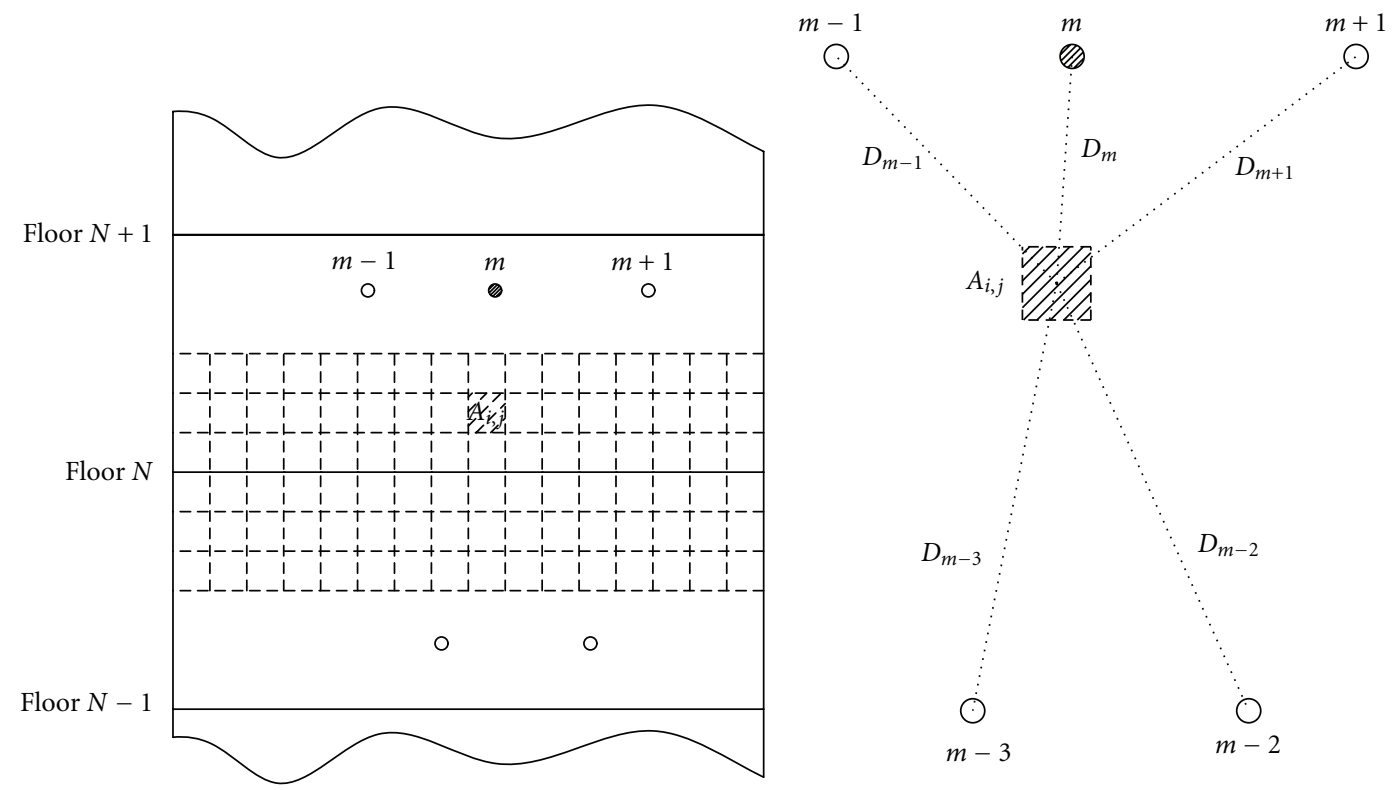

(a)

(b)

Figure 7: Wind load estimation from pressure data: the tributary area of floor $N$ was divided into smaller areas; pressure forces acting on each smaller area, $A_{i, j}$, were calculated based on pressure data at the nearest pressure tap, $m$.

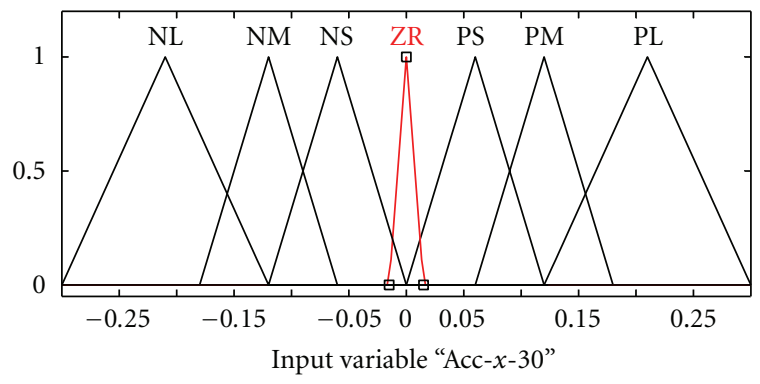

(a)

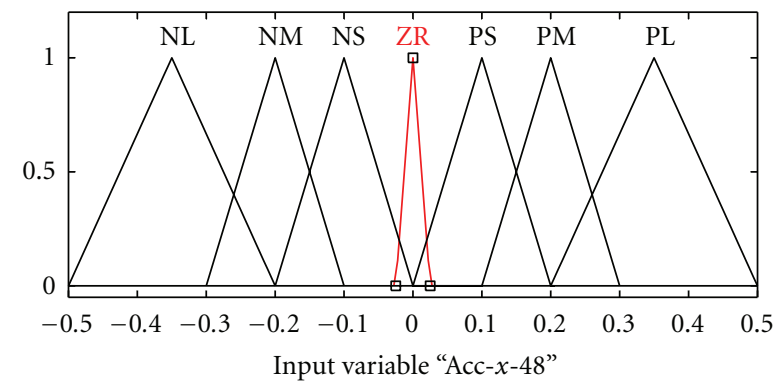

(c)

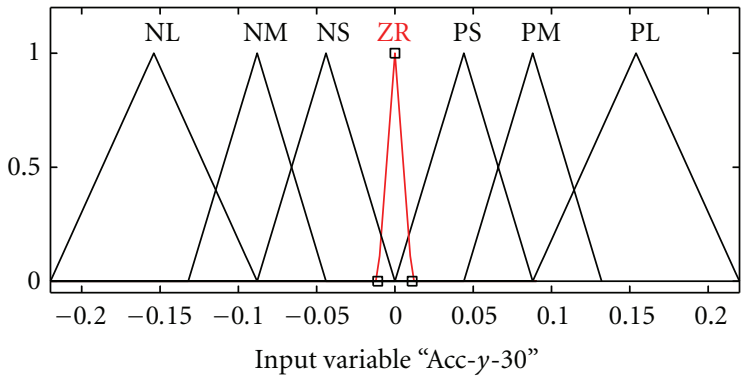

(b)

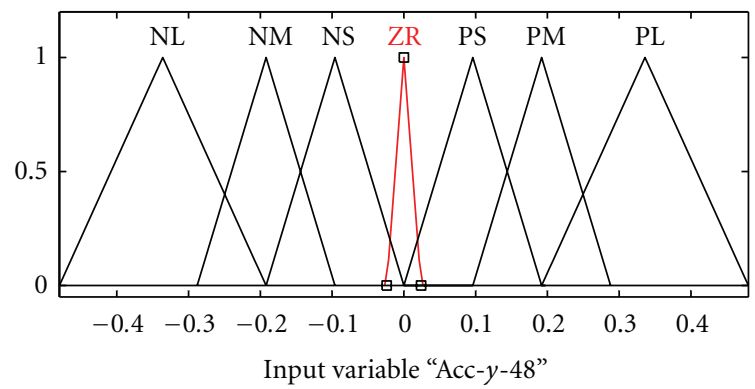

(d)

Figure 8: Membership functions for the input measured accelerations in the $x$-direction (Acc- $x$-30, Acc- $x$ - 48 ) and the $y$-direction (Acc- $y$ 30, Acc- $y-48)$.

loads are

$$
\mathbf{M} \ddot{\mathbf{X}}+\mathbf{C X}+\mathbf{K X}=\mathbf{F}(t)
$$

where $\mathbf{X}=[\mathbf{x} \mathbf{y}]^{T}$ is a $2 n \times 1$ vector and $n$ is the number of nodes, while $\mathbf{x}$ and $\mathbf{y}$ are vectors of nodal displacements in $x$ and $y$ directions, respectively. $\mathbf{F}(t)=\left[\begin{array}{ll}\mathbf{F}_{x}(t) & \mathbf{F} y(t)\end{array}\right]^{T}$, in which $\mathbf{F}_{x}(t)$ and $\mathbf{F}_{y}(t)$ are $n \times 1$ vectors of external forces acting in $x$ and $y$ directions, respectively. Using the first $N$ modes obtained by FEM with the next transformation

$$
\mathrm{X}=\Phi \mathbf{Q}
$$




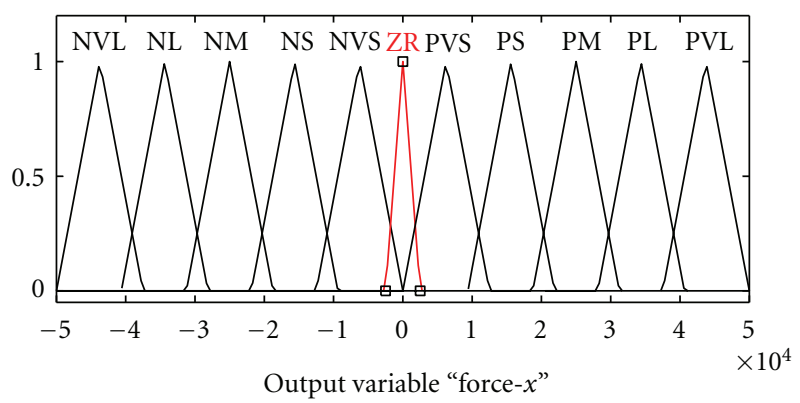

(a)

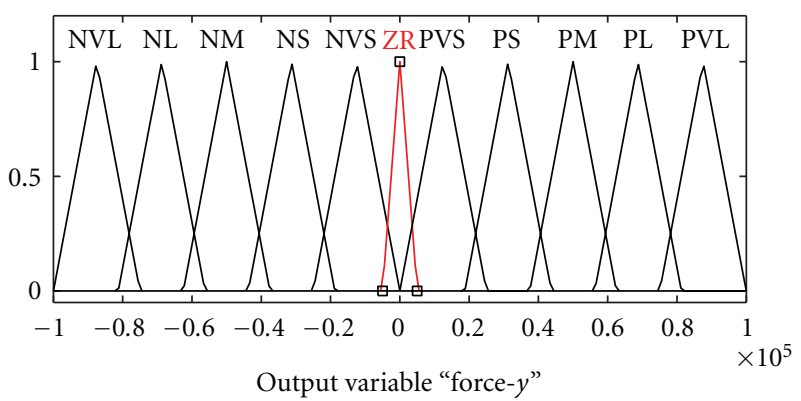

(b)

FIGURE 9: Membership functions for the output control force in the $x$-direction (Force- $x$ ) and the $y$-direction (Force- $y$ ).

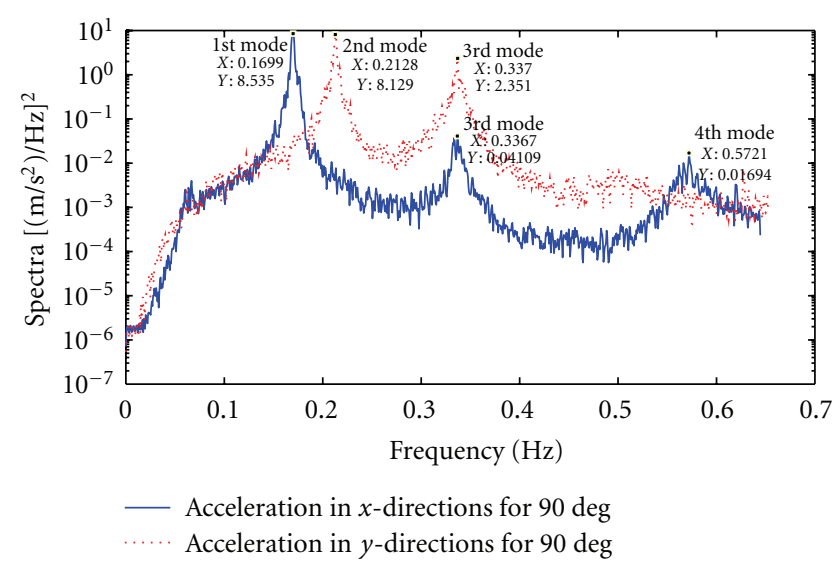

Figure 10: Power spectra of the acceleration response of the top corner of the building in the two lateral directions.

where $\Phi$ is $2 n \times N$ matrix of eigenvectors and $\mathbf{Q}$ is $N \times 1$ vector of generalized displacements; that is,

$$
\boldsymbol{\Phi}=\left[\begin{array}{cccc}
\phi_{1}\left(x_{1}\right) & \phi_{2}\left(x_{1}\right) & \cdots & \phi_{N}\left(x_{1}\right) \\
\phi_{1}\left(x_{2}\right) & \phi_{2}\left(x_{2}\right) & \cdots & \phi_{N}\left(x_{2}\right) \\
\vdots & \vdots & & \vdots \\
\phi_{1}\left(x_{n}\right) & \phi_{2}\left(x_{n}\right) & \cdots & \phi_{N}\left(x_{n}\right) \\
\phi_{1}\left(y_{1}\right) & \phi_{2}\left(y_{1}\right) & \cdots & \phi_{N}\left(y_{1}\right) \\
\phi_{1}\left(y_{2}\right) & \phi_{2}\left(y_{2}\right) & \cdots & \phi_{N}\left(y_{2}\right) \\
\vdots & \vdots & & \vdots \\
\phi_{1}\left(y_{n}\right) & \phi_{2}\left(y_{n}\right) & \cdots & \phi_{N}\left(y_{n}\right)
\end{array}\right],
$$

Substituting by (2) into (1) and premultiplying by $\boldsymbol{\Phi}^{T}$, one obtains

$$
\boldsymbol{\Phi}^{T} \mathbf{M} \Phi \ddot{\mathbf{Q}}+\boldsymbol{\Phi}^{T} \mathbf{C} \Phi \dot{\mathbf{Q}}+\boldsymbol{\Phi}^{T} \mathbf{K} \Phi \mathbf{Q}=\boldsymbol{\Phi}^{T} \mathbf{F}(t) .
$$

By assuming the damping matrix, $\mathrm{C}$, to be proportional damping, (4) results into six uncoupled equations

$$
\begin{aligned}
m_{11} \ddot{q}_{1} & +c_{11} \dot{q}_{1}+k_{11} q_{1} \\
= & \sum_{i=1}^{n} \Phi_{1}\left(x_{i}\right) F_{x, i}(t)+\sum_{i=1}^{n} \Phi_{1}\left(y_{i}\right) F_{y, i}(t)=G F_{1}, \\
m_{22} \ddot{q}_{2}+ & c_{22} \dot{q}_{2}+k_{22} q_{2} \\
= & \sum_{i=1}^{n} \Phi_{2}\left(x_{i}\right) F_{x, i}(t)+\sum_{i=1}^{n} \Phi_{2}\left(y_{i}\right) F_{y, i}(t)=G F_{2}, \\
& \vdots \\
m_{N N} \ddot{q}_{N} & +c_{N N} \dot{q}_{N}+k_{N N} q_{N} \\
= & \sum_{i=1}^{n} \Phi_{N}\left(x_{i}\right) F_{x, i}(t)+\sum_{i=1}^{n} \Phi_{N}\left(y_{i}\right) F_{y, i}(t)=G F_{N},
\end{aligned}
$$

where $m_{i i}, c_{i i}, k_{i i}$, and $G F_{i}$ are generalized mass, generalized damping, generalized stiffness, and generalized force of the $i$ th mode, respectively. Using the measurements obtained by the pressure transducers, pressure coefficients (matrix $\mathbf{C}_{p}$ ) are evaluated at each tap location as a function of time. These values are used with the full-scale model to give the pressure distribution on the surface. The pressure values on the surface of the prototype can be calculated as

$$
\left.\mathbf{P}(\text { space, time })=\frac{1}{2} \rho U^{2} \mathbf{C}_{p} \text { (space, time }\right),
$$

where $\mathbf{P}$ (space,time) is a matrix containing the pressure values on the surface of the full scale model as a function of space $(x, y$, and $z)$ and time; $\rho$ is the air density which is assumed to be $1.25 \mathrm{~kg} / \mathrm{m}^{3}$ (according to [2]), and $U$ is the prototype mean wind speed. The wind load at any node of the outer surface is the integration of the pressure over the surface area in the vicinity of the node as

$$
\mathbf{F}(\text { nodes, time })=\int \mathbf{P}(\text { space }, \text { time }) d A \text {. }
$$




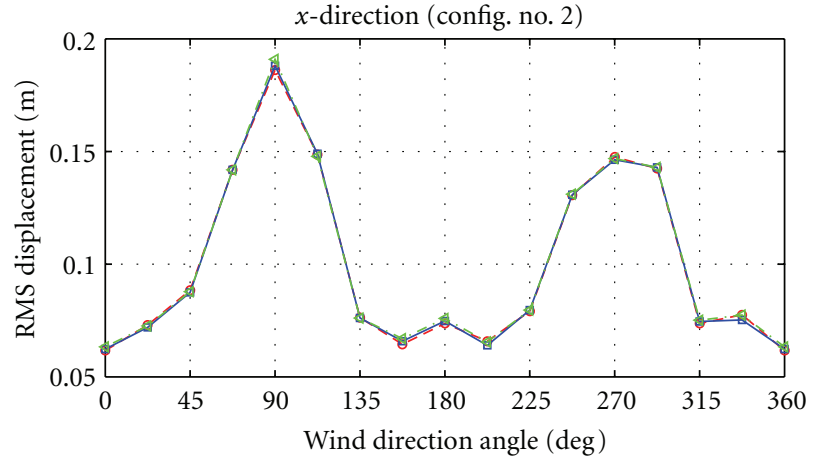

(a)

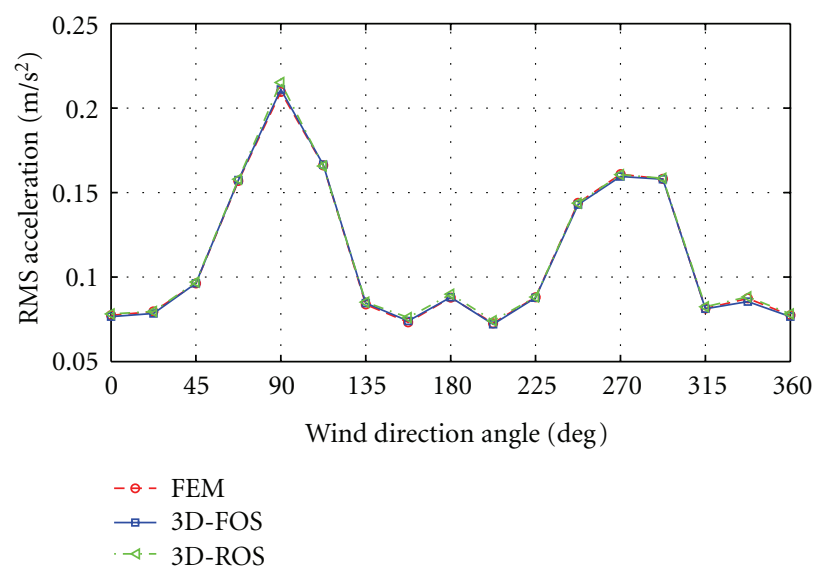

(c)

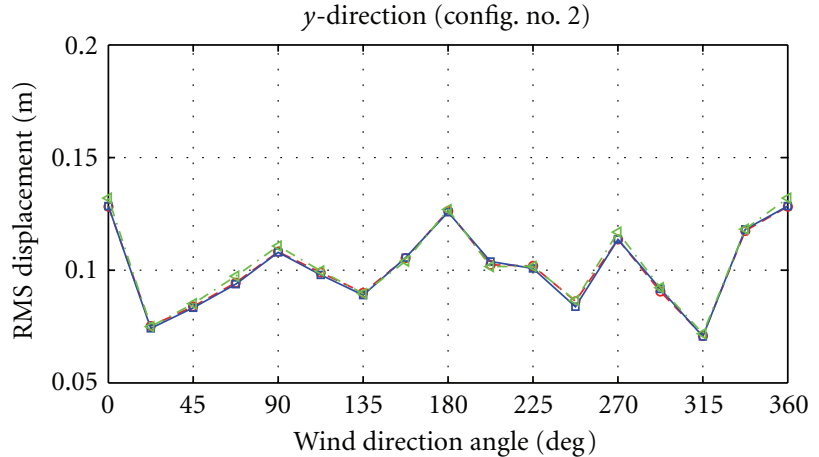

(b)

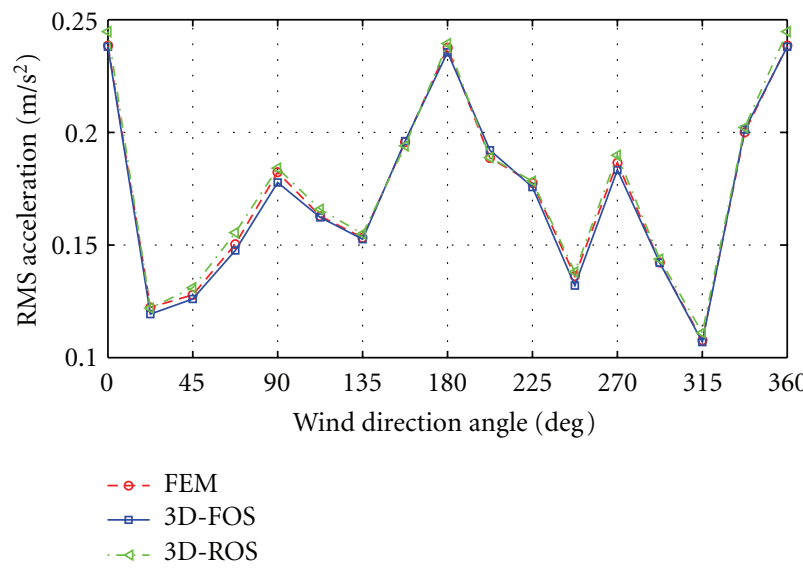

(d)

FIGURE 11: displacement and acceleration responses of a point at the top corner for FEM, 3D full order system (3D-FOS), and 3D reduced order system (3D-ROS).

TABLE 1: Modal parameters of the FEM model.

\begin{tabular}{lcccc}
\hline Mode number* & Generalized mass $\times 10^{7}\left(\mathrm{~kg} \cdot \mathrm{m}^{2}\right)$ & Generalized stiffness $\times 10^{9}(\mathrm{~N} \cdot \mathrm{m})$ & Frequency $(\mathrm{Hz})$ & Modal damping \\
\hline 1 & 1.2953 & 0.0147 & 0.1694 & 0.0102 \\
2 & 0.9937 & 0.0178 & 0.2132 & 0.0112 \\
3 & 0.4945 & 0.0222 & 0.3370 & 0.0150 \\
4 & 0.8724 & 0.1115 & 0.5689 & 0.0234 \\
5 & 0.8273 & 0.2153 & 0.8120 & 0.0326 \\
6 & 0.3544 & 0.1600 & 1.0695 & 0.0426 \\
\hline
\end{tabular}

* Modes 1 and 4 are lateral displacements in $x$-direction; modes 2 and 5 are lateral disp. in $y$-direction while modes 3 and 6 are torsion.

This means that once the time history of the pressures on the outer surfaces is calculated, the external forces acting on the nodes of the surface can be computed. The excitation forces acting on the internal nodes are of course equal to zero. The $q_{i}(t)$ are then solved from each of (5). SIMULINK is used for the numerical solution of these equations [29].

2.2. 3D Lumped Mass Model. For control purposes, a 3D lumped mass model is derived from the original FEM. In this model, the total mass of the building was assumed to be lumped at the positions of the floors, and it was assumed for the floors to perform a general 3D movement (each floor has two translations in the $x$ and $y$ directions in addition to the torsional rotation). The building alone (without the control devices) is modeled dynamically using a total of 144 degreeof-freedom. In general, the equations of motion for an $n$ story building moving in both the two transverse directions and in torsion are written as

$$
\mathbf{M}_{s} \ddot{\mathbf{x}}+\mathbf{C}_{s} \dot{\mathbf{x}}+\mathbf{K}_{s} \mathbf{x}=-\mathbf{F}+\mathbf{\Lambda} \mathbf{f},
$$

where $\mathbf{x}=[\mathbf{X} \mathbf{Y} \mathbf{\Theta}]^{T}$. The terms $\mathbf{X}=\left[\begin{array}{llll}x_{1} & x_{2} \cdots x_{n}\end{array}\right]$ and $\mathbf{Y}=\left[\begin{array}{llll}y_{1} & y_{2} & \cdots & y_{n}\end{array}\right]$ are row vectors of the displacements of the centre of mass of each floor in the $x$ and $y$ directions, respectively, and $\boldsymbol{\Theta}=\left[\theta_{1} \theta_{2} \cdots \theta_{n}\right]$ is the vector of the rotations of each floor about the vertical axis ( $z$-axis) while 


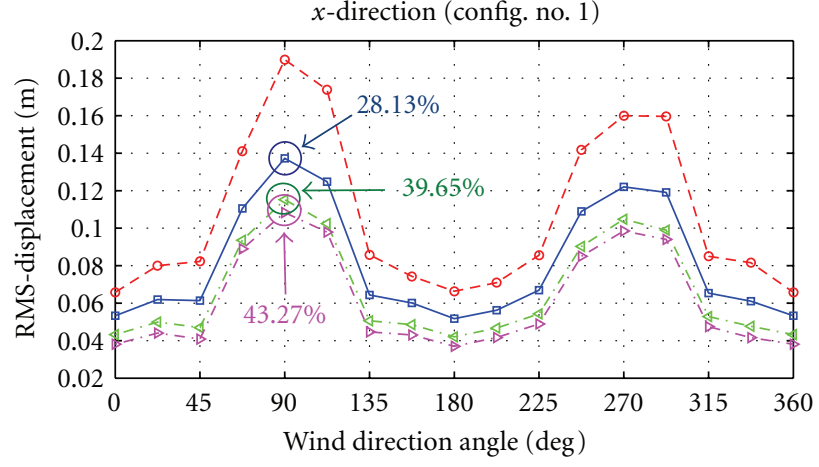

(a)

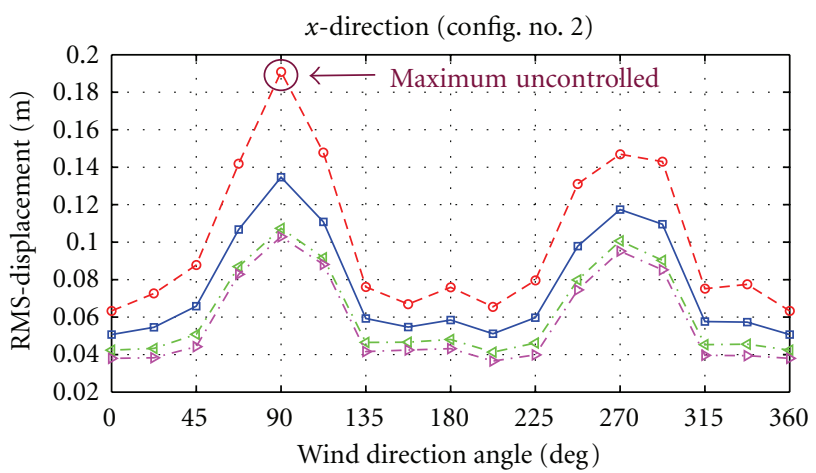

$-\ominus-$ Uncontrolled

$\rightarrow$ TMD

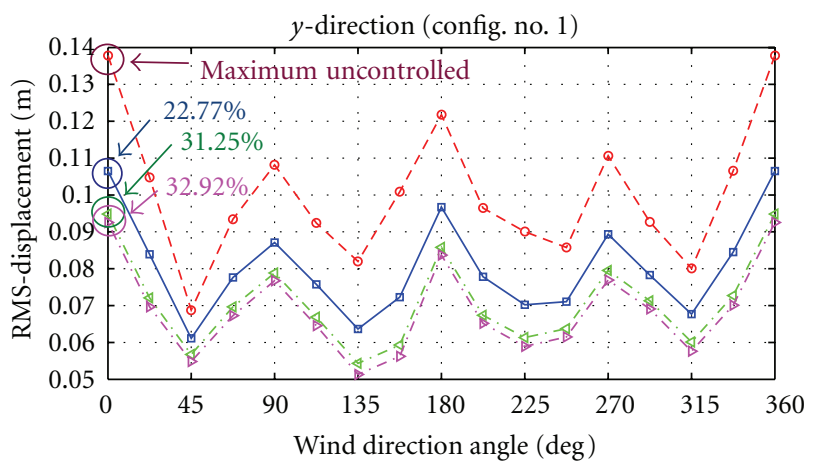

(b)

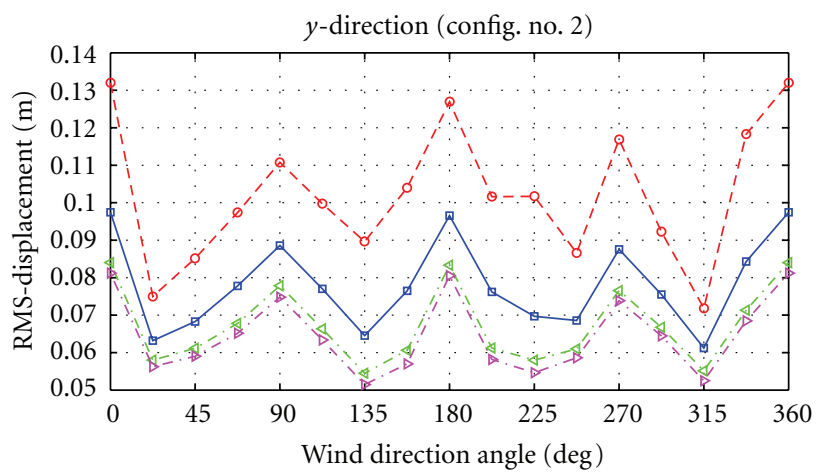

$-\ominus-$ Uncontrolled

$\rightarrow$ TMD
$\triangleleft-\operatorname{ATMD}(\mathrm{LQR})$

$\rightarrow-\operatorname{ATMD}$ (fuzzy)

(c)

(d)

FIgURE 12: RMS-displacements of the top corner of the tower.

$n$ is the number of stories. The mass matrix, $\mathbf{M}_{s}$, and the stiffness matrix, $\mathbf{K}_{s}$, have the following form:

$$
\mathbf{M}_{s}=\left[\begin{array}{ccc}
\mathbf{M} & \mathbf{0} & \mathbf{0} \\
\mathbf{0} & \mathbf{M} & \mathbf{0} \\
\mathbf{0} & \mathbf{0} & \mathbf{I}
\end{array}\right], \quad \mathbf{K}_{s}=\left[\begin{array}{ccc}
\mathbf{K}_{x} & \mathbf{0} & \mathbf{0} \\
\mathbf{0} & \mathbf{K}_{y} & \mathbf{0} \\
\mathbf{0} & \mathbf{0} & \mathbf{K}_{\theta}
\end{array}\right],
$$

where $\mathbf{M}=\operatorname{diag}\left(\left[m_{1} m_{2} \cdots m_{n}\right]\right)$ is a diagonal matrix of lumped masses, $\mathbf{I}=\operatorname{diag}\left(\left[\begin{array}{llll}I_{1} & I_{2} & \cdots & I_{n}\end{array}\right]\right)$ in which $I_{i}$ is the moment of inertia of the $i$ th floor, $\mathbf{K}_{x}, \mathbf{K}_{y}$, and $\mathbf{K}_{\theta}$ are the stiffness matrices in the transverse directions $(x$ and $y)$ and the torsional direction, respectively. The stiffness matrix of the spatial model (3D lumped mass model) is obtained by assuming the stiffness between floors as a combination of cantilever and shear rigidities. MATLAB codes (MATLAB 2008; [29]) were written and used to derive the best stiffness matrix that gives the closest mode shapes to those of the FEM and the same first six natural frequencies. In (8), the disturbance $\mathbf{F}=\left[\begin{array}{lll}\mathbf{F}_{x} & \mathbf{F}_{y} & \mathbf{T}\end{array}\right]^{T}$ is a vector of excitation in which $\mathbf{F}_{x}$ and $\mathbf{F}_{y}$ are two vectors of the horizontal loads acting in the $x$ and $y$ directions, respectively, and $\mathrm{T}$ is a vector of the external torsional wind loads. Also, $\mathbf{f}$ is the vector of control forces, where its coefficient matrix $\Lambda$ is the matrix determined by the location of control devices.

Wind loading vectors $\left(\mathbf{F}_{x}, \mathbf{F}_{y}\right.$, and $\left.\mathbf{T}\right)$ lumped at the position of floors are obtained from wind tunnel pressure tests conducted at the wind tunnel of Politecnico di Milano [30] on a scaled 1:100 rigid model of the tower. Such largescale allows for the advantage of testing the model at high Reynolds number with minimum blockage due to the huge dimensions of the test section. Pressure taps were distributed on the outer surface of the test model. To allow for sufficient pressure measurements (see [7]), 400 taps were mapped on the outer surface of the model. Pressure taps were distributed to cover the entire outer surface with more intense at the upper part of the test model (see Figure 5(a)). Pressure data were acquired at a frequency of $62.5 \mathrm{~Hz}$ using 448 pressure taps. Figure 6 shows a typical spectrum of measured pressure data at model scale. Pressure data were integrated on the outer surface of the building (see Figure 5(b)) to obtain the corresponding time history of the two directional wind loads at each floor in addition to torsion. For the estimation of the wind loads at each floor, the tributary area for each floor was gridded into smaller areas and the time history of the wind loads at each area was found by using the Cp records of the closest pressure tap (see Figure 7). Codes were written in MATLAB to estimate the time histories of the wind forces acting at the center of each smaller area. After that, the floor forces in the two directions were obtained from the summation of the forces in each lateral direction. The torsion at each floor was the resultant of the summation of the force moments about the floor center. The surrounding buildings 


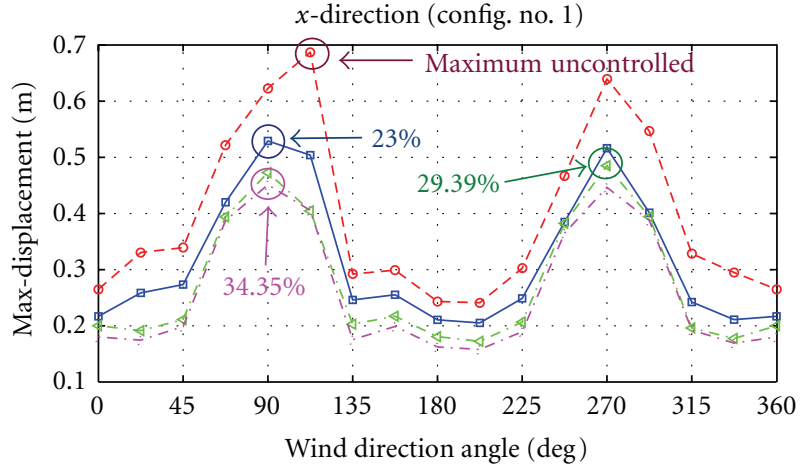

(a)

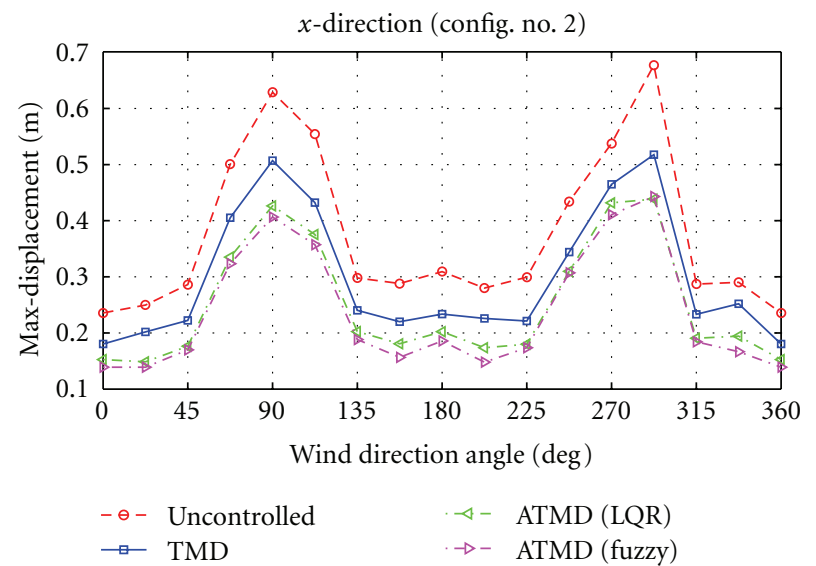

(c)

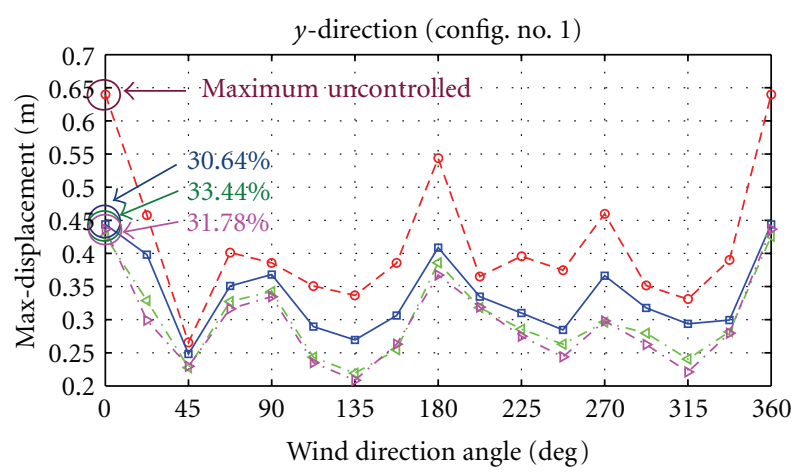

(b)

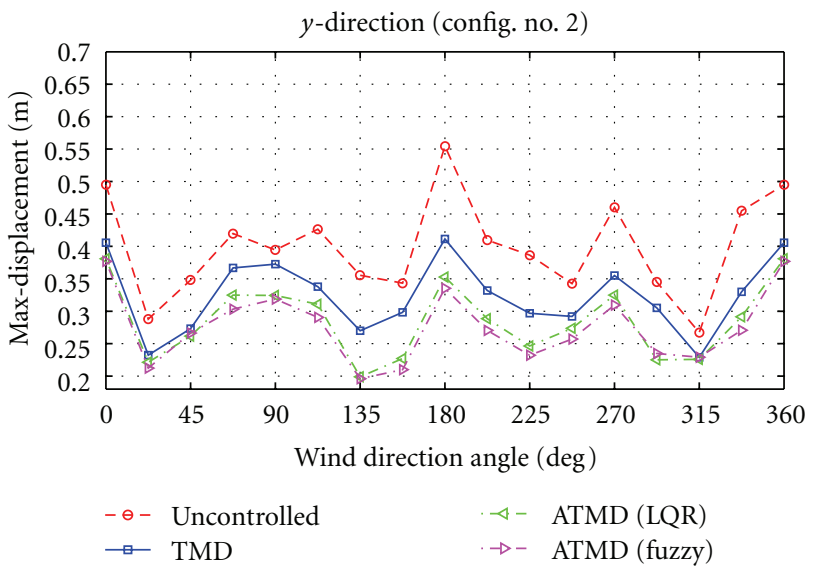

(d)

FIGURE 13: Maximum displacements of the top corner of the tower.

within a radius of $500 \mathrm{~m}$ from the centre of the tower were also scaled 1:100 to be presented on the turning test table according to the type of the test configuration used. The wind profile represents a typical urban terrain as shown in Figure 3 [31]. The reference mean wind speed $\left(U_{\text {ref }}=\right.$ $15 \mathrm{~m} / \mathrm{s}$ ) was measured at a height of $1 \mathrm{~m}$. Prototype reference mean wind speed is assumed to be $30 \mathrm{~m} / \mathrm{s}$. The target for the wind profiles is the Eurocode 1 [2]. The turbulence intensities in the longitudinal, lateral, and vertical directions are referred to by $I_{u}, I_{v}$, and $I_{w}$, respectively. Two different test configurations with the same wind profile are considered in this paper (see Figure 4). In the first configuration, the building is subjected to the wind load without the existence of other tall buildings, and is referred to as Config. no. 1. In the second configuration, the rigid model of the building was tested with the existence of all the surrounding buildings. This configuration is referred to as Config. no. 2. Further details about the wind tunnel experiment are given in Aly [24].

Due to the fact that the building's mass is symmetrical, and the study is based on the assumption that the structure is responding in the linear region, the lateral and the torsional behavior of the building may be studied alone, then the response time histories may be combined simultaneously. In this study, the plane motion of the structure in the $x$ direction is controlled using both the TMDs and ATMDs.
However, due to the fact that the control of the response in the $x$-direction will not affect the response of the building in the $y$-direction, another TMD and ATMD are designed to control the lateral in-plane response in the $y$-direction. Following that, the uncontrolled torsional response is added simultaneously to the two lateral responses to give the overall response in the two lateral directions.

The state reduction approach derived by Davison [32] and summarized later in Wu et al. [33] is used in this study (also see $\mathrm{Lu}$ et al. [20]). In this approach, the 48 degreeof-freedom (DOF) in-plane system is reduced to $15 \mathrm{DOF}$, where the first 30 modes are retained [23]. Note that the condition for this approach was that the response in terms of displacements and accelerations of the 15 DOF and 48 DOF are very much the same (see Section 4 ). This model is referred to as the reduced order system (ROS). The addition of the TMD increases the DOF to 16. The system with the TMD is referred to as ROS-TMD. In a similar task, ROSATMD refers to the ROS utilizing ATMD.

The state equation of the ROS that corresponds to the full order system (FOS) in (8) can be expressed as

$$
\dot{\mathbf{z}}=\mathbf{A z}+\mathbf{B} f+\mathbf{E w},
$$

in which $\mathbf{z}=\left[\overline{\mathbf{X}}^{\prime} ; \dot{\mathbf{X}}^{\prime}\right]$ is the 32-dimensional state vector, $\overline{\mathbf{X}}$ is a vector of the in-plane displacements of floors $3,6,9,12$, 


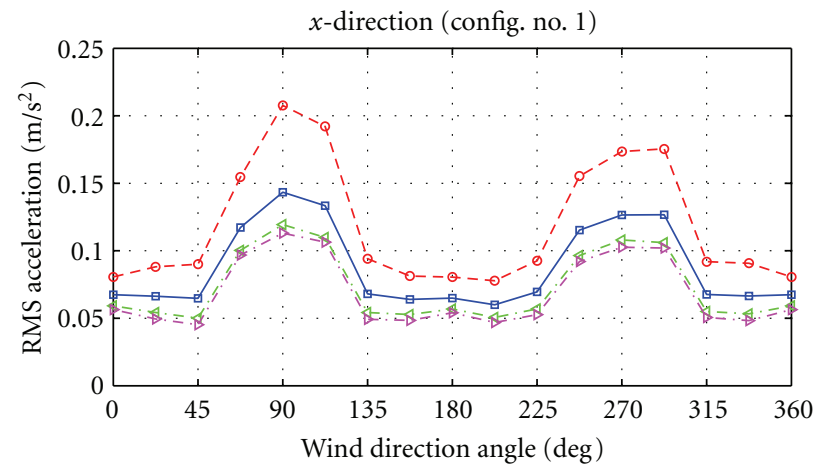

(a)

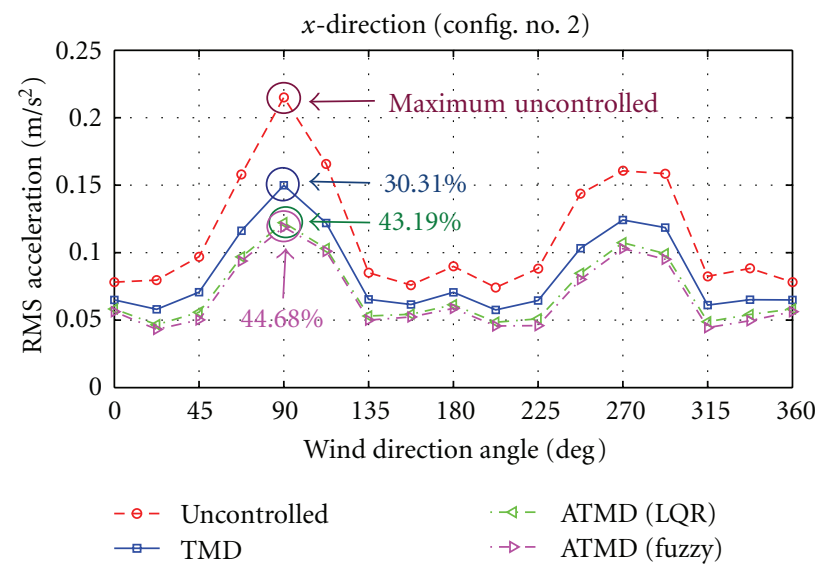

(c)

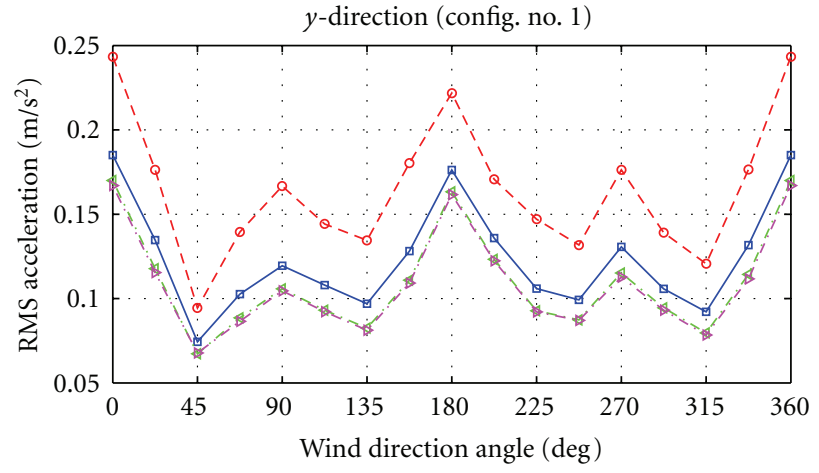

(b)

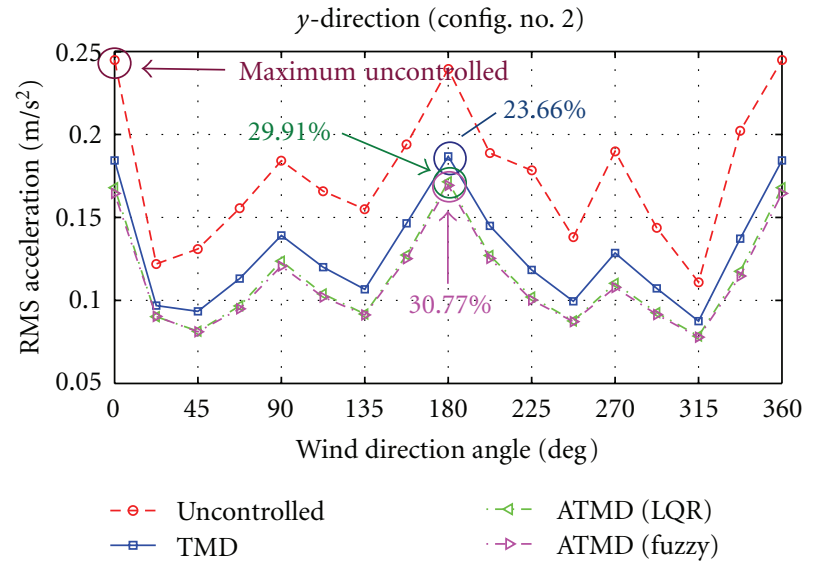

(d)

FIGURE 14: RMS accelerations of the top corner of the tower.

$16,19,22,26,29,32,35,38,41,44$, and 48 in addition to the displacement of the inertial mass of the damper. $\mathbf{A}$ is a $(32 \times 32)$ system matrix, $\mathbf{B}$ is a 32 location vector, and $\mathbf{E}$ is a 32 excitation vector. In the system reduction above, the wind loads acting on each of the 15 floors above are computed from the wind loads $\mathbf{F}$ acting on each of the 48 floors by lumping wind forces on adjacent floors at the locations that correspond to the 15 DOF model.

The controlled output vector, $\mathbf{y}_{c}$, and the measured output, $\mathbf{y}_{m}$, of the ROS described by (10) can be expressed as

$$
\begin{aligned}
\mathbf{y}_{c} & =\mathbf{C}_{c} \mathbf{z}+\mathbf{D}_{c} f+\mathbf{F}_{c} \mathbf{w}_{x}, \\
\mathbf{y}_{m} & =\mathbf{C}_{m} \mathbf{z}+\mathbf{D}_{m} f+\mathbf{F}_{m} \mathbf{w}_{x}+\nu,
\end{aligned}
$$

where $\mathbf{C}_{c}, \mathbf{D}_{c}, \mathbf{F}_{c}, \mathbf{C}_{m}, \mathbf{D}_{m}$, and $\mathbf{F}_{m}$ are matrices with appropriate dimensions and $v$ is the measurement noise vector. The model used for controller design was further reduced as follows:

$$
\begin{aligned}
\dot{\mathbf{z}}_{r} & =\mathbf{A}_{r} \mathbf{z}_{r}+\mathbf{B}_{r} f+\mathbf{E}_{r} \mathbf{w}_{x}, \\
\mathbf{y}_{c r} & =\mathbf{C}_{c r} \mathbf{z}_{r}+\mathbf{D}_{c r} f+\mathbf{F}_{c r} \mathbf{w}_{x}, \\
\mathbf{y}_{m r} & =\mathbf{C}_{m r} \mathbf{z}_{r}+\mathbf{D}_{m r} f+\mathbf{F}_{m r} \mathbf{w}_{x}+v_{r},
\end{aligned}
$$

where $\mathbf{z}_{r}$ is a 6-dimensional state vector of the reduced order system, $\mathbf{y}_{c r}$ is a controlled output vector identical of $\mathbf{y}_{c}$ defined by (11), $\mathbf{y}_{m r}$ is the measured output vector; $v_{r}$ is the measurement noise, and $\mathbf{C}_{c r}, \mathbf{D}_{c r}, \mathbf{F}_{c r}, \mathbf{C}_{m r}, \mathbf{D}_{m r}$, and $\mathbf{F}_{m r}$ are appropriate matrices.

\section{Controllers and Limitations}

In this study, both TMDs and ATMDs are used for the reduction of the lateral responses of the building. However, in order to make the design of such control systems more realistic and applicable, the following restrictions and assumption are applied.

(i) The mass of the TMD in the $x$-direction is 100 ton, while the mass of the TMD in the $y$-direction is 150 ton. Such restrictions are applied to avoid excessive weight on the roof (the overall mass on the roof is about $0.625 \%$ of the overall building's mass).

(ii) The TMDs are tuned to the first vibrational mode in each corresponding lateral direction. The damping factor is taken to be $20 \%$ of the critical. This amount of damping is selected higher than the optimal value for the sake of restricting the stroke of the ATMDs.

(iii) The maximum stroke of the actuators is restricted to $1.5 \mathrm{~m}$. 


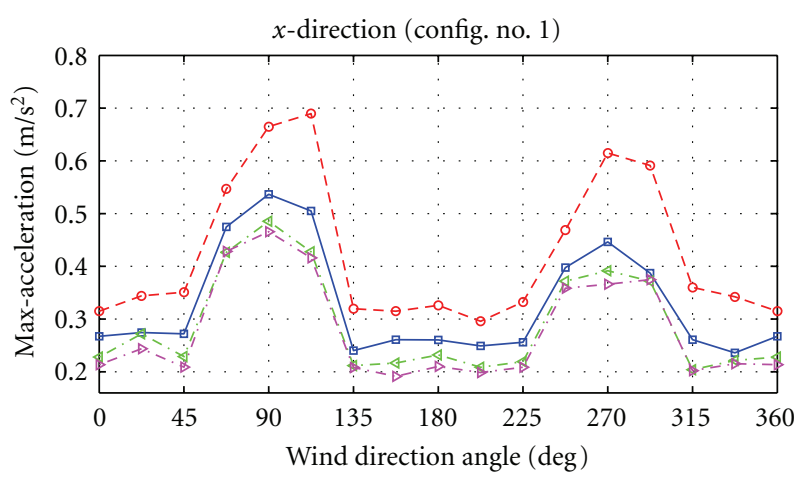

(a)

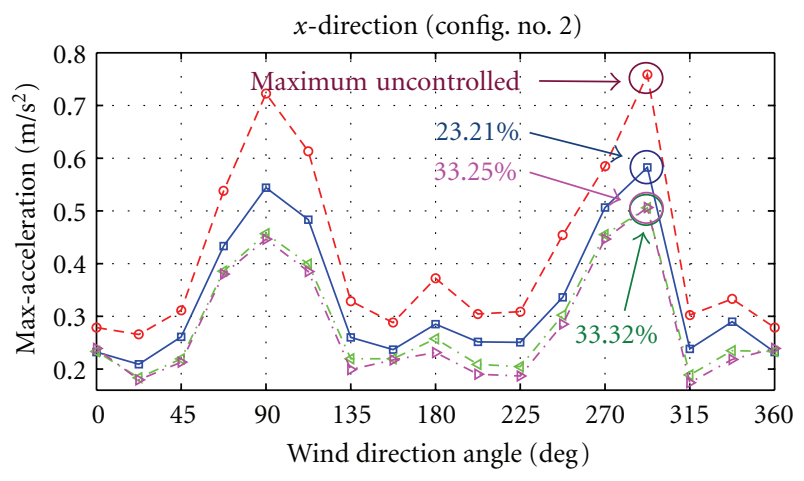

(c)

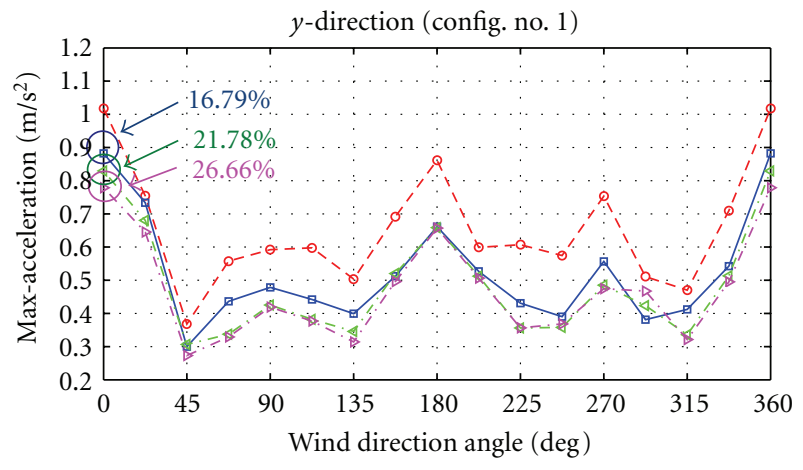

(b)

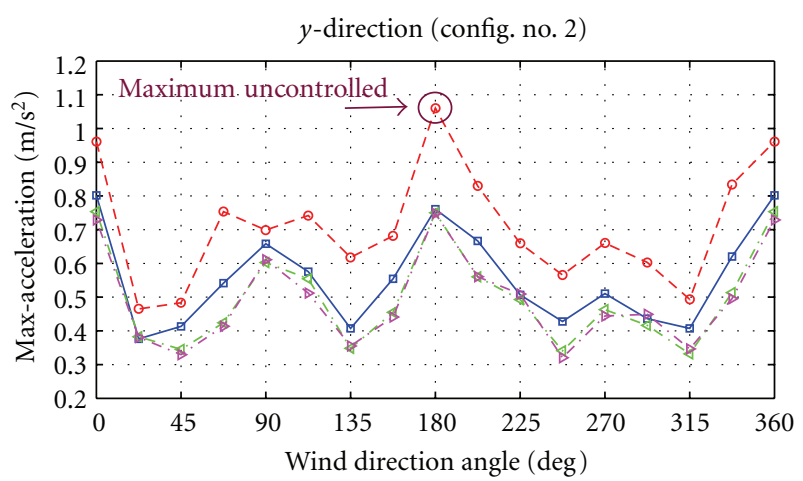

(d)

FIgURE 15: Maximum accelerations of the top corner of the tower.

(iv) The maximum control force of the actuator in the $y$ direction is restricted to $100 \mathrm{kN}$, and that in the $x$ direction is restricted to $25 \mathrm{kN}$.

(v) The computational delay and the sampling rate of the digital controller are $0.001 \mathrm{~s}$.

(vi) Three acceleration measurements are available for each lateral direction (at floor 30, roof, and mass of the TMD).

Note that the tower required a TMD with heavier mass and ATMD with higher control force in one lateral direction than the other, which was basically attributed to geometry. A linear-quadratic regulator (LQR) design with output weighting is selected to give the desired control force using the MATLAB function (lqry.m). The state-feedback law $f=$ $-G z_{r}$ minimizes the cost function

$$
J(f)=\int_{0}^{\infty}\left(\mathbf{y}_{c r}^{\prime} \mathbf{Q} \mathbf{y}_{c r}+f^{\prime} \mathbf{R} f\right) d t,
$$

where $G$ is the feedback gain matrix, $z_{r}$ is a 6-dimensional state vector of the reduced order system, $\mathbf{y}_{c r}$ is the measured output vector, the symbol (') denotes transpose, and $\mathbf{Q}$ and $\mathbf{R}$ are weighting matrices. Parametric studies were performed with various weighting matrices $\mathbf{Q}$, corresponding to various regulated output vectors. The results of these parametric studies indicated that an effective controller could be designed by selecting a vector of regulated responses to include the velocities of each floor.
For comparison reasons, fuzzy logic controllers are used in this study to command the actuators of the ATMDs (see Nguyen et al. [34]). From a design point of view, fuzzy logic controllers do not require the complexity of a traditional control system. The measured accelerations can be used directly as input to the fuzzy controller. The main advantages of using a fuzzy control algorithm are summarized in Battaini et al. [35] and Samali et al. [36]. According to Samali et al. [36], uncertainties of input data are treated in a much easier way by fuzzy control theory than by classical control theory. Since fuzzy controllers are based on linguistic synthesis, they possess inherent robustness. Fuzzy controllers can be easily implemented in a fuzzy chip with immediate reaction time and autonomous power supply. Furthermore, the design of fuzzy controller does not require state reduction or concerning about observers. Only two acceleration measurements were used (floor 30 and roof).

The input variables to the fuzzy controller were selected as accelerations of floors 30 and 48 and the output as the control force. The membership functions for the inputs were defined and selected as seven triangles with overlaps as shown in Figure 8. For the output, they were defined and selected as nine triangles with overlaps as shown in Figure 9. The fuzzy variables used to define the fuzzy space are ZR (zero), PVS (positive very small), PS (positive small), PM (positive medium), PL (positive large), PVL (positive very large), NVS (negative very small), NS (negative small), NM (negative medium), NL (negative large), and NVL (negative 
TABLE 2: Control rule base [36].

\begin{tabular}{lccccccc}
\hline $\begin{array}{l}\text { Acceleration } \\
\text { of 48th floor }\end{array}$ & NL & NM & NS & ZR & PS & PM & PL \\
\hline NL & PVL & PVL & PL & PVS & ZR & ZR & ZR \\
NM & PL & PL & PM & PVS & ZR & ZR & ZR \\
NS & ZR & NVS & PM & PS & PVS & ZR & ZR \\
ZR & ZR & ZR & NVS & ZR & PVS & ZR & ZR \\
PS & ZR & ZR & NVS & NS & NM & PVS & ZR \\
PM & ZR & ZR & ZR & NVS & NM & NL & NL \\
PL & ZR & ZR & ZR & NVS & NL & NVL & NVL \\
\hline
\end{tabular}

very large). The rule-base for computing the desired current is presented in Table 2 [36].

\section{Results and Discussion}

Table 3 gives the response of the top corner of the building in the $y$-direction for an incident angle of $0^{\circ}$ under different consideration of mode shapes. It is shown that the displacement response of this building is dominated by the first lateral mode in the $y$-direction (modes $1: 2$ in the table). Nevertheless, this underestimates the displacement response by $3 \%$ to $4.4 \%$ and the acceleration response by about $12 \%$ to $17 \%$. Note that the aspect ratio of this building in the $y$-direction is about 11 . This means that for very slender buildings, the solo consideration of the first lateral mode may lead to significant error in the estimation of the response, especially for the acceleration response. Table 4 lists the response of the top corner of the tower in the $x$-direction for an incident angle of $90^{\circ}$ under different consideration of mode shapes. It is shown that the displacement and acceleration response are dominated by the first lateral mode in the $x$ direction (modes 1 in the table). Note that the aspect ratio of this building in the $x$-direction is about 3.6. This means that for buildings with low aspect ratio, the solo consideration of the first lateral mode may be sufficient for the estimation of the response. Figure 10 shows the power spectra of the acceleration response of the top corner of the building in the two lateral directions. The figure shows that the third mode (torsion) contributes significantly to the acceleration in the $y$-direction. In general, results given by the figure, Tables 3 and 4 show that the responses of tall buildings under winds are dominated by the first few modes (for this specific building, the first two lateral modes and the first torsional mode can be sufficient).

Figure 11 gives displacement and acceleration responses of a point at the top corner of the building for the FEM, the $3 \mathrm{D}$ full order system (3D-FOS), and the 3D reduced order system (3D-ROS). The figure shows that the response in terms of displacements and accelerations of the three types of modeling are very much the same (see Section 4). This means that FE modeling, 3D lumped mass modeling, and 3D reduced order modeling of tall buildings under wind loads can give an accurate assessment of the response provided that the first dominant modes are retained. The figure shows also that the cross-wind response is higher than the alongwind response. This reveals the importance of the procedure proposed in this study as many design codes and formula may provide accurate estimate of the along-wind response but less guidance for the estimation of the critical cross-wind and torsional response. The results show that the building is very much vulnerable to wind loads. This may be due to its low weight and its low dominant frequencies.

The building required a TMD with heavier mass and ATMD with higher control force in one lateral direction than the other. This may be attributed to geometry. Figures 1114 show the controlled and uncontrolled responses of the tower under wind loads for two test configurations at different incident angles. Two examples of control are considered, TMDs and ATMDs with LQR and fuzzy logic controllers. For each example, the controlled responses in the $x$ and $y$ directions are plotted with the uncontrolled responses. The controlled and uncontrolled responses of the tower are evaluated by simulations [29]. Four evaluation criteria are used to examine the performance of the proposed controllers. Evaluation criteria include: rms displacements, maximum displacements, rms accelerations, and maximum accelerations of the top corner of the tower in the two lateral directions. The figures are superimposed by ellipses indicating the position of the most unfavourable responses (uncontrolled, with TMDs, with ATMDs (LQR), and with ATMDs (fuzzy)) over the two configurations in both $x$ and $y$ directions. The amount of reduction in the highest response achieved by TMDs and ATMDs over the worst uncontrolled response is indicated in the figures.

Figures 11 and 12 give controlled and uncontrolled rms displacements and max displacements of the top corner of the tower in both the $x$ and $y$ directions. It is shown that TMDs have a great effect on the reduction of the displacement response of the building. Reductions achieved by TMDs in the displacements responses range from 22-30\% over the worst uncontrolled response. Generally, TMDs are able to give good reduction in the rms displacements in both the $x$ and $y$ directions for all wind incident angles. Reductions achieved by ATMDs in the displacement responses range from $29 \%-43 \%$ over the worst uncontrolled response. ATMDs with fuzzy logic controllers are able to enhance the reduction in the displacement responses over LQR (perhaps $\mathrm{Q}$ and $\mathrm{R}$ could be more optimal) most of the time (by about $1 \%$ to $5 \%$ ). They also have a general similar trend over all of the wind attack angles.

Figures 13 and 14 give controlled and uncontrolled rms accelerations and maximum accelerations (Figure 15) of the top corner of the tower in both the $x$ and $y$ directions. It is shown that the TMDs have a significant effect on the reduction of the acceleration response of the building. Reductions achieved by TMDs in the acceleration responses range from $16 \%-30 \%$ over the worst uncontrolled response.

Generally, TMDs are able to give good reduction in the rms displacements in both the $x$ and $y$ directions for all the wind incident angles. However, the performance is limited in reducing the along-wind maximum acceleration of the tower in the $y$-direction under Config. no. 2, when the wind direction angle is $90^{\circ}$. This may be due to the interference 
TABLE 3: Response of the top corner of the tower in the $y$-direction for an incident angle of $0^{\circ}$.

\begin{tabular}{lcccc}
\hline Mode & RMS-disp. $(\mathrm{m})$ & Max-disp. $(\mathrm{m})$ & RMS-accel. $\left(\mathrm{m} / \mathrm{s}^{2}\right)$ & Max-accel. $\left(\mathrm{m} / \mathrm{s}^{2}\right)$ \\
\hline 1 & $0.000(-100 \%)$ & $0.001(-99.8 \%)$ & $0.000(100 \%)$ & $0.001(-99.9 \%)$ \\
$1: 2$ & $0.129(-4.4 \%)$ & $0.587(-2.8 \%)$ & $0.199(-17.1 \%)$ & $0.855(-11.8 \%)$ \\
$1: 3$ & $0.136(0.7 \%)$ & $0.613(1.5 \%)$ & $0.238(-0.8 \%)$ & $0.980(1.1 \%)$ \\
$1: 4$ & $0.136(0.7 \%)$ & $0.613(1.5 \%)$ & $0.238(-0.8 \%)$ & $0.980(1.1 \%)$ \\
$1: 5$ & $0.135(0 \%)$ & $0.606(0.3 \%)$ & $0.239(-0.4 \%)$ & $0.966(-0.3 \%)$ \\
$1: 6$ & $0.135(0 \%)$ & $0.604(0 \%)$ & $0.240(0 \%)$ & $0.969(0 \%)$ \\
\hline
\end{tabular}

TABLE 4: Response of the top corner of the tower in the $x$-direction for an incident angle of $90^{\circ}$.

\begin{tabular}{lcccc}
\hline Mode & RMS-disp. $(\mathrm{m})$ & Max-disp. $(\mathrm{m})$ & RMS-accel. $\left(\mathrm{m} / \mathrm{s}^{2}\right)$ & Max-accel. $\left(\mathrm{m} / \mathrm{s}^{2}\right)$ \\
\hline 1 & $0.188(1.1 \%)$ & $0.646(-0.5 \%)$ & $0.203(-0.5 \%)$ & $0.654(-3.5 \%)$ \\
$1: 2$ & $0.188(1.1 \%)$ & $0.646(-0.5 \%)$ & $0.203(-0.5 \%)$ & $0.654(-3.5 \%)$ \\
$1: 3$ & $0.187(0.5 \%)$ & $0.648(-0.2 \%)$ & $0.204(0 \%)$ & $0.653(-3.7 \%)$ \\
$1: 4$ & $0.186(0 \%)$ & $0.649(0 \%)$ & $0.204(0 \%)$ & $0.676(-0.3 \%)$ \\
$1: 5$ & $0.186(0 \%)$ & $0.649(0 \%)$ & $0.204(0 \%)$ & $0.676(-0.3 \%)$ \\
$1: 6$ & $0.186(0 \%)$ & $0.649(0 \%)$ & $0.204(0 \%)$ & $0.678(0 \%)$ \\
\hline
\end{tabular}

effects of two high-rise buildings in the oncoming wind (see Figure 4). Results also show that ATMDs are able to enhance the reduction in the responses. Reductions achieved by ATMDs in the acceleration responses range from $21 \%-$ $43 \%$ over the worst uncontrolled response. ATMDs with fuzzy logic controllers are able to enhance the reduction in the acceleration responses over LQR, and in general, they have a similar trend over all of the wind incident angles.

As a general comment on Figures 11-14, one can see that the performance of the controllers is much better in the $x$-direction. In addition, the capability of the controllers to reduce the responses (especially maximum accelerations at angles $0^{\circ}$ and $180^{\circ}$ ) in the $y$-direction is limited. This may be due to the effect of vortex shedding on the across-wind responses. Moreover, the structure is slender in $x$-direction (see Figure 2). The structure is also stiffer in the $y$-direction (see Table 1 for natural frequencies). However, the procedure presented in this study permits the response of tall buildings to be assessed and controlled in the preliminary design stages which can help decision makers, involved in the design process, to choose among innovative design solutions like structural control, considering several damping techniques, modifying geometry, or even changing materials (e.g., from steel to concrete).

\section{Conclusions}

The paper presents practical procedure for the response prediction and reduction in high-rise buildings under wind loads. To show the applicability of the procedure, aerodynamic loads acting on a quasirectangular high-rise building based on an experimental approach (surface pressure measurement) are used with a mathematical model of the structure for the response prediction and reduction. The building represents a case study of an engineered design of a very slender tower that is instructive. The contributions of this paper can be summarized as follows.
(1) The methodology based on HFPI and FEM proposed for the estimation of the response of highrise buildings under wind loads has the advantage of combining lateral along-wind, lateral cross-wind, and torsional responses altogether. The technique allows for the consideration of any number of modes.

(2) Results show that the responses of tall buildings under winds are dominated by the first few modes. Consequently, FEM, 3D lumped mass modeling, and reduced order $3 \mathrm{D}$ modeling of tall buildings under wind loads give an accurate assessment of the response provided that the first dominant modes are retained.

(3) Results show that the response of tall buildings in the cross-wind direction (lateral response combined simultaneously with torsion) can be higher than the response in the along-wind direction. This reveals the importance of the procedure proposed in this study as many design codes and formula may provide accurate estimate of the along-wind response but less guidance for the estimation of the critical cross-wind and torsional response.

(4) The building represents an engineered steel design of a structure that is very much vulnerable to wind loads. This may be due to its low weight as well as high flexibility related to the low dominant frequencies and the high aspect ratio.

(5) The building demands TMD with heavier mass and ATMD with higher control force in one lateral direction than the other. This may be attributed to geometry.

(6) For the purpose of the use of active control, LQR and fuzzy logic controllers are shown to be effective in enhancing the response reduction over the TMD. ATMDs with fuzzy logic controllers show similar 
trend like LQR controllers under multidirectional wind loads. In addition, from a design point of view, fuzzy logic controllers do not require the complexity of traditional control systems.

(7) The procedure presented in this paper permits the response of tall buildings to be assessed and controlled in the preliminary design stages. This can help decision makers, involved in the design process, to choose among innovative design solutions like structural control, considering several damping techniques, modifying geometry, or even changing materials.

\section{Acknowledgments}

The authors would like to express appreciation to the work team at the Wind Tunnel of Politecnico di Milano, Milan, Italy. The first author wishes to thank Ms Corey Ginsberg, Florida International University, for her helpful comments.

\section{References}

[1] American Society of Civil Engineers, Minimum Design Loads for Buildings and Other Structures, American Society of Civil Engineers, 2006.

[2] Eurocode 1, "Actions on structures-part 1-4: general actions-wind actions," European Standard prEN 1991-1-4, 2004.

[3] E. Simiu, "Wind loading codification in the Americas: fundamentals for a renewal," in Proceedings of the 11th Americas Conference on Wind Engineering, San Juan, Puerto Rico, USA, June 2009.

[4] S. X. Chen, "A more precise computation of along wind dynamic response analysis for tall buildings built in urban areas," Engineering, vol. 2, pp. 290-298, 2010.

[5] Y. Zhou, T. Kijewski, and A. Kareem, "Aerodynamic loads on tall buildings: interactive database," Journal of Structural Engineering, vol. 129, no. 3, pp. 394-404, 2003.

[6] D. K. Kwon, T. Kijewski-Correa, and A. Kareem, "E-analysis of high-rise buildings subjected to wind loads," Journal of Structural Engineering, vol. 134, no. 7, pp. 1139-1153, 2008.

[7] E. Simiu, R. D. Gabbai, and W. P. Fritz, "Wind-induced tall building response: a time-domain approach," Wind and Structures, vol. 11, no. 6, pp. 427-440, 2008.

[8] J. R. Wu, Q. S. Li, and A. Y. Tuan, "Wind-induced lateraltorsional coupled responses of tall buildings," Wind and Structures, vol. 11, no. 2, pp. 153-178, 2008.

[9] M. F. Huang, K. T. Tse, C. M. Chan et al., "An integrated design technique of advanced linear-mode-shape method and serviceability drift optimization for tall buildings with lateraltorsional modes," Engineering Structures, vol. 32, no. 8, pp. 2146-2156, 2010.

[10] K. T. Tse, P. A. Hitchcock, and K. C. S. Kwok, "Mode shape linearization for HFBB analysis of wind-excited complex tall buildings," Engineering Structures, vol. 31, no. 3, pp. 675-685, 2009.

[11] K. M. Lam and A. Li, "Mode shape correction for windinduced dynamic responses of tall buildings using timedomain computation and wind tunnel tests," Journal of Sound and Vibration, vol. 322, no. 4-5, pp. 740-755, 2009.

[12] J. T. P. Yao, "Concept of structural control," American Society of Civil Engineers Journal of the Structural Division, vol. 98, no. 7, pp. 1567-1574, 1972.
[13] G. W. Housner, L. A. Bergman, T. K. Caughey et al., "Structural control: past, present, and future," Journal of Engineering Mechanics, vol. 123, no. 9, pp. 897-971, 1997.

[14] Y. Zhou, D. Wang, and X. Deng, "Optimum study on windinduced vibration control of high-rise buildings with viscous dampers," Wind and Structures, vol. 11, no. 6, pp. 497-512, 2008.

[15] A. M. Aly and R. E. Christenson, "On the evaluation of the efficacy of a smart damper: a new equivalent energy-based probabilistic approach," Smart Materials and Structures, vol. 17, no. 4, Article ID 045008, 11 pages, 2008.

[16] A. M. Aly, A. Zasso, and F. Resta, "On the dynamics of a very slender building under winds: response reduction using MR dampers with lever mechanism," Structural Design of Tall and Special Buildings, vol. 20, no. 5, pp. 541-553, 2011.

[17] R. J. McNamara, "Tuned mass dampers for buildings," American Society of Civil Engineers Journal of the Structural Division, vol. 103, no. 9, pp. 1785-1798, 1977.

[18] R. J. Facioni, K. C. S. Kwok, and B. Samali, "Wind tunnel investigation of active vibration control of tall buildings," Journal of Wind Engineering and Industrial Aerodynamics, vol. 54-55, pp. 397-412, 1995.

[19] M. Gu and F. Peng, "An experimental study of active control of wind-induced vibration of super-tall buildings," Journal of Wind Engineering and Industrial Aerodynamics, vol. 90, no. 1215, pp. 1919-1931, 2002.

[20] L. T. Lu, W. L. Chiang, J. P. Tang, M. Y. Liu, and C. W. Chen, "Active control for a benchmark building under wind excitations," Journal of Wind Engineering and Industrial Aerodynamics, vol. 91, no. 4, pp. 469-493, 2003.

[21] T. T. Soong, Active Structural Control. Theory and Practice, Longman, New York, NY, USA, 1990.

[22] J. C. Wu and B. C. Pan, "Wind tunnel verification of actively controlled high-rise building in along-wind motion," Journal of Wind Engineering and Industrial Aerodynamics, vol. 90, no. 12-15, pp. 1933-1950, 2002.

[23] A. M. Aly, F. Resta, and A. Zasso, "Active control in a high-rise building under multidirectional wind loads," in Proceedings of the SEI Structures Congress, Vancouver, Canada, 2008.

[24] A. M. Aly, On the dynamics of buildings under winds and earthquakes: response prediction and reduction, Ph.D. thesis, Department of Mechanical Engineering, Politecnico di Milano, Milan, Italy, 2009.

[25] C. Li, B. Han, J. Zhang, Y. Qu, and J. Li, "Active multiple tuned mass dampers for reduction of undesirable oscillations of structures under wind loads," International Journal of Structural Stability and Dynamics, vol. 9, no. 1, pp. 127-149, 2009.

[26] A. Mohtat, A. Yousefi-Koma, and E. Dehghan-Niri, "Active vibration control of seismically excited structures by ATMDS: stability and performance robustness perspective," International Journal of Structural Stability and Dynamics, vol. 10, no. 3, pp. 501-527, 2010.

[27] S. J. Park, J. Lee, H. J. Jung, D. D. Jang, and S. D. Kim, “Numerical and experimental investigation of control performance of active mass damper system to high-rise building in use," Wind and Structures, vol. 12, no. 4, pp. 313-332, 2009.

[28] S. Homma, J. Maeda, and N. Hanada, "The damping efficiency of vortex-induced vibration by tuned-mass damper of a towersupported steel stack," Wind and Structures, vol. 12, no. 4, pp. 333-347, 2009.

[29] S. Attaway, Matlab: A Practical Introduction to Programming and Problem Solving, Butterworth-Heinemann, Amsterdam, The Netherlands, 2009. 
[30] G. Diana, S. De Ponte, M. Falco, and A. Zasso, "New large wind tunnel for civil environmental and aeronautical applications," Journal of Wind Engineering and Industrial Aerodynamics, vol. 74-76, pp. 553-565, 1998.

[31] A. Zasso, S. Giappino, S. Muggiasca, and L. Rosa, "Optimization of the boundary layer characteristics simulated at Politecnico di Milano boundary layer wind tunnel in a wide scale ratio ranger," in Proceedings of the 6th Asia-Pacific Conference on Wind Engineering, Seoul, Korea, September 2005.

[32] E. J. Davison, "A method for simplifying linear dynamic systems," IEEE Transactions on Automatic Control, vol. 11, no. 1, pp. 93-101, 1966.

[33] J. C. Wu, J. N. Yang, and W. E. Schmitendorf, "Reducedorder $\mathrm{H} \infty$ and LQR control for wind-excited tall buildings," Engineering Structures, vol. 20, no. 3, pp. 222-236, 1998.

[34] H. T. Nguyen, R. P. Nadipuram, C. L. Walker, and E. A. Walker, A First Course in Fuzzy and Neural Control, Chapman \& Hall/CRC, Boca Raton, Fla, USA, 2003.

[35] M. Battaini, F. Casciati, L. Faravelli et al., "Control algorithm and sensor location," in Proceedings of the 2nd World Conference on Structural Control, pp. 1391-1398, Kyoto, Japan, June 1998.

[36] B. Samali, M. Al-Dawod, K. C. Kwok, and F. Naghdy, "Active control of cross wind response of 76-story tall building using a fuzzy controller," Journal of Engineering Mechanics, vol. 130, no. 4, pp. 492-498, 2004. 

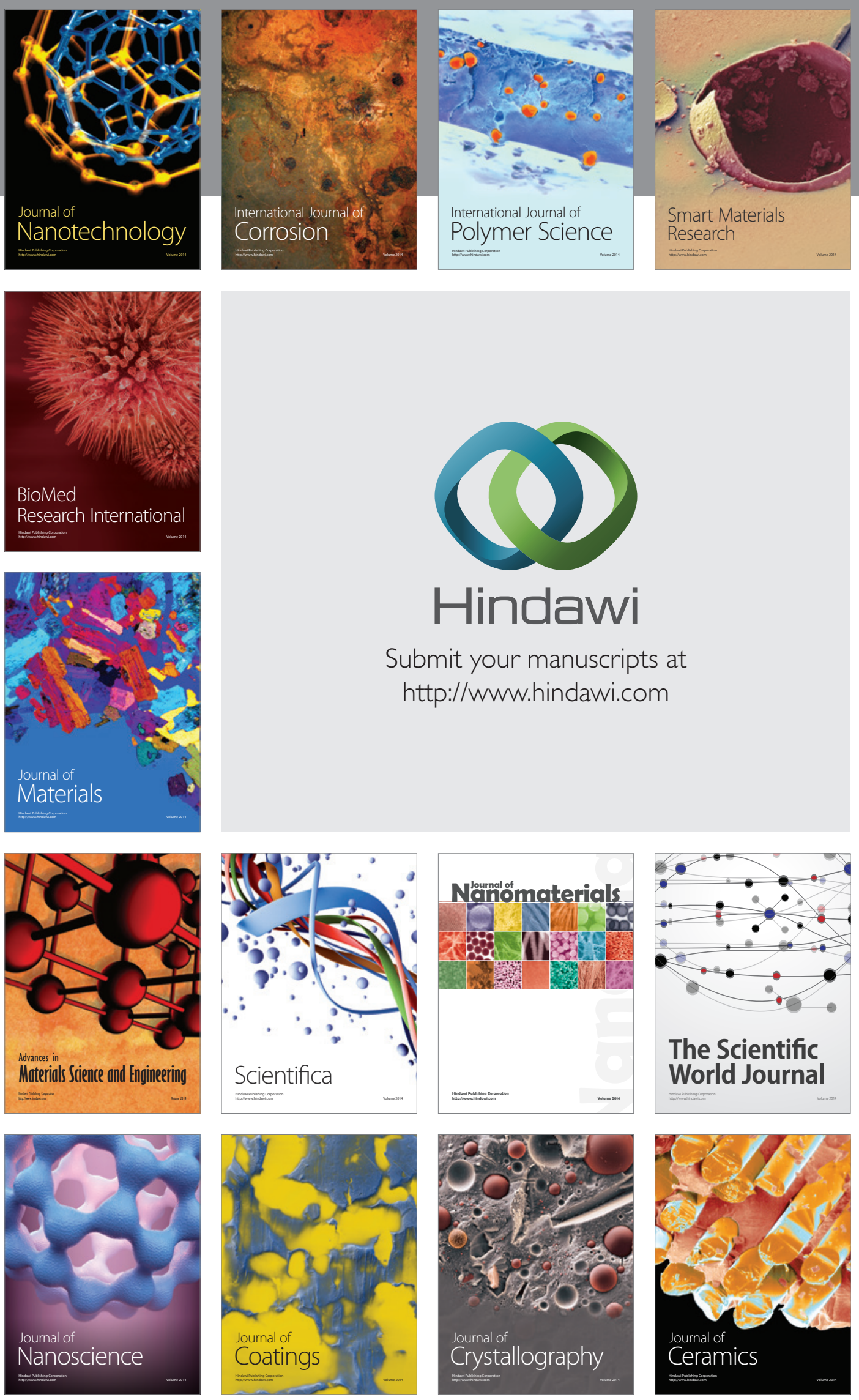

The Scientific World Journal

Submit your manuscripts at

http://www.hindawi.com

\section{World Journal}

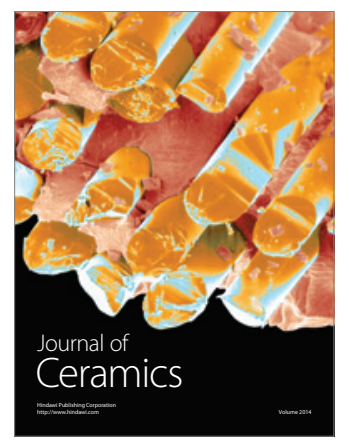

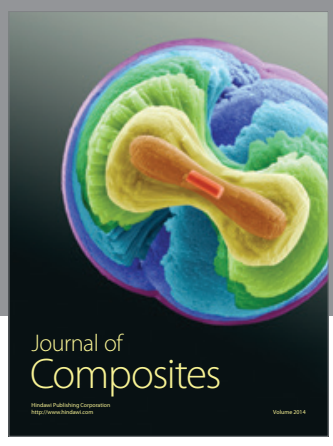
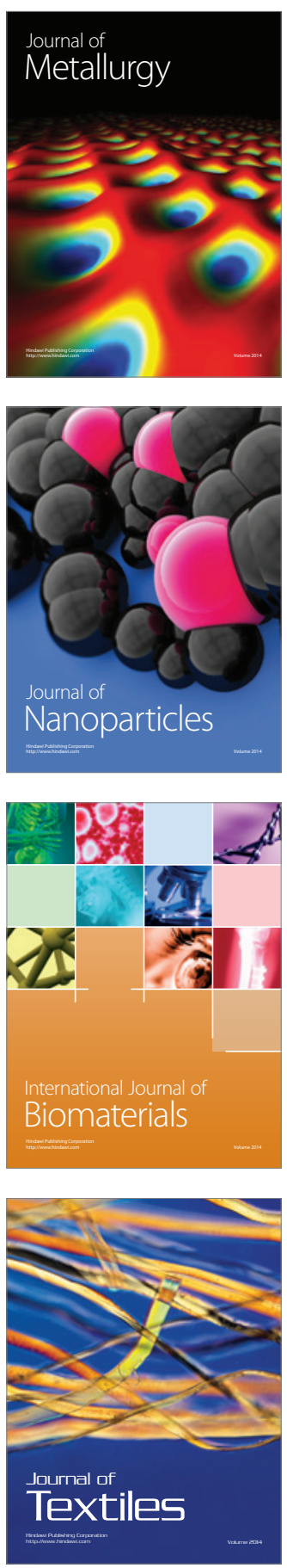